\title{
A coupled hydrodynamic-structural model of the M4 wave energy converter
}

DOI:

10.1016/j.jfluidstructs.2016.02.009

\section{Document Version}

Accepted author manuscript

Link to publication record in Manchester Research Explorer

\section{Citation for published version (APA):}

Eatock Taylor, R., Taylor, P. H., \& Stansby, P. (2016). A coupled hydrodynamic-structural model of the M4 wave energy converter. JOURNAL OF FLUIDS AND STRUCTURES, 63, 77. [21].

https://doi.org/10.1016/j.jfluidstructs.2016.02.009

\section{Published in:}

JOURNAL OF FLUIDS AND STRUCTURES

\section{Citing this paper}

Please note that where the full-text provided on Manchester Research Explorer is the Author Accepted Manuscript or Proof version this may differ from the final Published version. If citing, it is advised that you check and use the publisher's definitive version.

\section{General rights}

Copyright and moral rights for the publications made accessible in the Research Explorer are retained by the authors and/or other copyright owners and it is a condition of accessing publications that users recognise and abide by the legal requirements associated with these rights.

\section{Takedown policy}

If you believe that this document breaches copyright please refer to the University of Manchester's Takedown Procedures [http://man.ac.uk/04Y6Bo] or contact uml.scholarlycommunications@manchester.ac.uk providing relevant details, so we can investigate your claim.

\section{OPEN ACCESS}




\title{
A coupled hydrodynamic-structural model of the M4 wave energy converter
}

\author{
R. Eatock Taylor ${ }^{\mathrm{a}, *}$, P.H. Taylor ${ }^{\mathrm{a}}$, P.K. Stansby ${ }^{\mathrm{b}}$ \\ a Department of Engineering Science, University of Oxford, Oxford OX1 3PJ, UK \\ b School of Mechanical, Aerospace and Civil Engineering, University of Manchester, Manchester M13 9PL, UK
}

\section{A R T I C L E I N F O}

\section{Article history:}

Received 6 May 2015

Accepted 29 February 2016

\section{Keywords:}

Wave energy

Fluid-structure interaction

Wave diffraction

Substructuring

Modal analysis

\begin{abstract}
A B S T R A C T
A method is developed for modelling wave energy converters consisting of floats connected by slender structural elements. The hydrodynamic and structural dynamic analyses are separated in a two-stage process, though the model is fully coupled. The method of dynamic substructuring is used to achieve this separation. The linear diffraction/ radiation problem is solved with a finite element idealisation for axisymmetric floats, and drag forces are incorporated by equivalent linearization. Results for a planar representation of the M4 device, and comparisons of theory and experiments undertaken for two scale models tested in regular and random waves, confirm the validity of the theoretical approach. A series of parametric studies is performed to clarify the important physical variables, including natural periods, the ratio of a characteristic length of the device to the wave length, and power take-off.
\end{abstract}

(c) 2016 Elsevier Ltd. All rights reserved.

\section{Introduction}

In recent years the topic of wave energy has received much attention in the technical literature, and there have been several valuable reviews of the resource (for example Bryden, 2006; EPRI, 2011; Arinaga and Cheung, 2012), and technological developments (e.g. Falnes, 2007; Cruz, 2008; Greaves et al, 2009; Falcão, 2010). A wide range of devices has been proposed for harnessing wave energy (as reviewed for example in López et al. (2013) and Babarit et al. (2012)), and appropriate numerical methods for modelling and methods of benchmarking have also been subjected to extensive examination and review (e.g. Babarit et al., 2012; Wolgamot and FitzGerald, 2015). Out of these various reviews have emerged suggestions for classifying wave energy converters according to their geometric form and their principles of operation. Widely used is the distinction between overtopping devices; terminators; attenuators; and point absorbers (e.g. Wolgamot and FitzGerald, 2015). But these authors and others have also pointed out that some of the more promising devices do not readily fit into such a scheme of classification. The system under investigation in the present paper is such a device. It has a long articulated spine and points into the waves, so has some of the attributes of an attenuator (such as described by Yemm et al. (2012) and Farley et al. (2012)). The spine, however, is supported by individual floats, which have characteristics of point absorbers (see for example Evans and Porter (2012)). The aim of the present paper is use a coupled method to provide some of the theoretical background to explain how the device operates, leading to its good power output as measured against standard metrics such as capture width (Evans, 1981).

\footnotetext{
* Corresponding author.

E-mail address: r.eatocktaylor@eng.ox.ac.uk (R. Eatock Taylor).
} 
There are 3 collinear axisymmetric floats in the M4 wave energy converter, each separated from its neighbour by about half a wave length at the optimal operating condition. The bow and mid float are rigidly connected, and the significantly larger stern float is attached to the mid float by an articulated joint at which power is generated by the relative angular motions of those two floats. The relevant motion of each float involves a combination of heave, pitch and surge. The progression down wave from small to medium to large floats serves to keep the heading of the device roughly aligned with the incident waves. The half wave length spacing is intended to optimise the anti-phase forcing on adjacent floats, hence maximising the angular motions at the joint. The near-trapping phenomenon however (e.g. Evans and Porter, 1997; Wolgamot et al., 2014), through which for an array of equally sized and spaced floats very large hydrodynamic responses can arise at certain critical wave frequencies, does not play a significant part in the behaviour of the device. Some of the details of its design principles have been explained by Stansby et al. (2015a), which together with Stansby et al. (2014, 2015b) also give results from experiments at two scales in regular and irregular waves. Fig. 1 shows the elevation of one of the experimental models of the initial concept, and Fig. 2 illustrates the relative motions of the floats when excited by a wave.

Stansby et al. (2015a) have also outlined a theoretical model, in which the (linear) hydrodynamic parameters are evaluated using the diffraction analysis software WAMIT, and dynamic response of the device in the vertical plane is obtained by a time-stepping procedure. This was used to assist in optimising the device performance in regular long-crested waves. For the results given here, we use a different method to develop the model, which is slightly simpler in the hydrodynamic representation: an axisymmetric diffraction analysis (as summarised in Eatock Taylor et al. (2009)) is used for each float, but there is assumed to be no hydrodynamic interaction between them. The modelling of the system dynamics, however, is more detailed, in that the connecting members can be assumed to be flexible. This is achieved by using the two-stage approach described by Sun et al. (2011, 2012). The first stage is the hydrodynamic analysis of the floats, considered as independent rigid bodies. Analysis of the structural dynamics of the mechanical interaction between the floats is then undertaken in the second stage: in this, the method of substructuring (also known as the master-slave approach) is used to condense out all structural degrees of freedom except those describing the motions of the rigid floats.

Details of the method of analysis are given in Section 2. The model is essentially linear, intended for investigating performance of the device under operational conditions. It is clear however that if the floats are flat-bottomed, as shown in Fig. 1, drag forces need to be included in the model. This is achieved by an iterative process using an approximation by equivalent linearization. As the emphasis here is on the geometric parameters governing the device, the power take-off is modelled simply as a linear damper. The resulting model is intended to be simple and efficient to use in exploring the design space for power capture from the device, and to highlight the significance of some key parameters. It is not suggested that this would be sufficient for detailed design, particularly where extreme wave conditions must be investigated. It is expected that at that stage (as discussed for example by Wolgamot and Fitzgerald (2015)) a fully nonlinear analysis may be appropriate, including full hydrodynamic interactions and modelling the details of what may be a nonlinear control system. It may also be considered desirable then to undertake limited CFD studies to develop a much more detailed assessment of how viscous effects influence the response of the device.

Application of the numerical model to different devices in the M4 family is illustrated in Section 3, where some comparisons are made with experimental measurements at two different scales. This section also includes some parametric

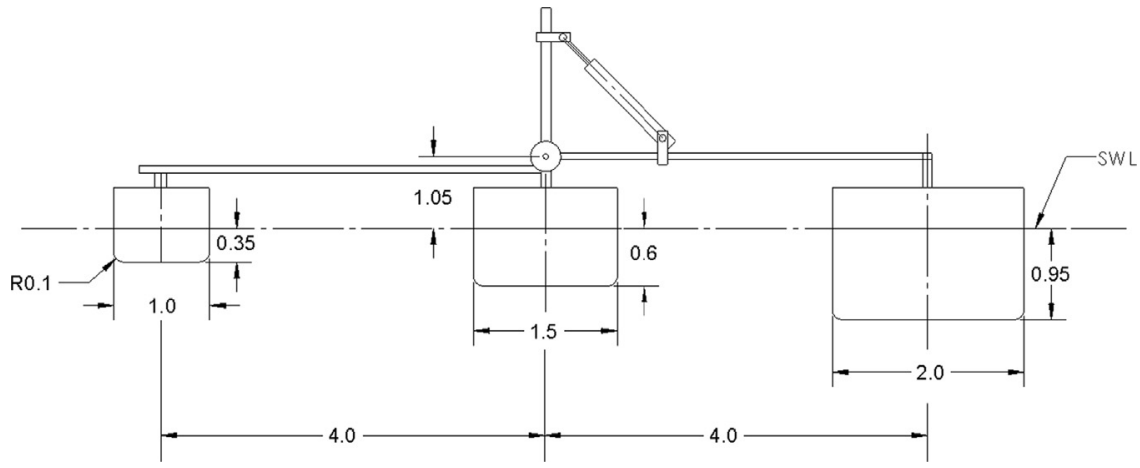

Fig. 1. Elevation of experimental model of initial concept with flat ends.

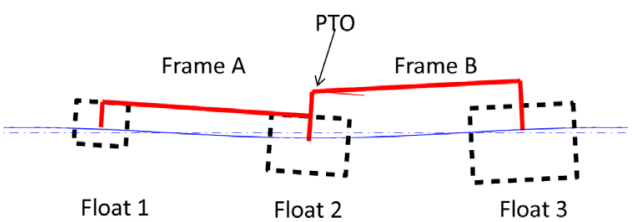

Fig. 2. Sketch showing motions of floats during the passage of a wave. 
studies which highlight the influence of drag damping, and how the performance of the device is related to the power takeoff coefficient. Further parametric studies are described in Section 4, examining the influence of the float separation and the incident wave direction. This section also includes a preliminary investigation of the effect of the flexibility of the structure connecting the floats. Some conclusions are drawn in Section 5. The potential for achieving greater power take-off from the device, through incorporation of additional flexibility leading to significant responses in extra degrees of freedom, remains an open question. The model presented is well suited to investigating such a possibility.

\section{General features of the analysis}

\subsection{Definition of the degrees of freedom in the model}

The model is assumed to consist of a group of floating bodies which are rigid but connected by flexible structural members, as shown in Fig. 1. At one (or more) joints, two adjacent members are connected by a linear or non-linear damper, representing the power take-off system (PTO). In the following, we assume for simplicity that there is just one PTO, and we will at times refer to the joint where it acts as a hinge (though other configurations are possible for absorbing power from relative motions of the two adjacent members). The floats are connected to frames on the two sides of the PTO, the frames being associated with the identifiers $A$ and $B$ respectively.

For generality we first assume that there are $N$ floats which can respond in up to $6 N$ rigid body degrees of freedom, represented by the vectors $\mathbf{X}_{\mathrm{AF}}$ and $\mathbf{X}_{\mathrm{BF}}$ for frames A and B respectively. It is convenient to define $\mathbf{X}_{\mathrm{AF}}$ and $\mathbf{X}_{\mathrm{BF}}$ in terms of the motions of a point at the centre of the water plane area of each float. At the joint containing the hinge, the six connected degrees of freedom are first considered separately, and designated $\mathbf{X}_{\mathrm{AH}}$ and $\mathbf{X}_{\mathrm{BH}}$. The remaining degrees of freedom of frames A and B, associated with the flexible structures assumed to connect the floats to the hinge, are $\mathbf{X}_{\mathrm{AC}}$ and $\mathbf{X}_{\mathrm{BC}}$.

\subsection{Application of substructuring}

The aim of the device is to extract power from the relative motion of the groups of floats $\mathrm{A}$ and $\mathrm{B}$, responding to the excitation from ambient waves. The analysis aims to quantify the theoretical power generated in a given sea state, as well as providing information on responses of the floats and stresses in the connecting structure. This may be conveniently achieved by using the method of dynamic substructuring with static condensation (see for example Przemieniecki (1985) and Sun et al. (2012)). This is applied separately to each frame. The degrees of freedom at the hinge, $\mathbf{X}_{\mathrm{AH}}$ and $\mathbf{X}_{\mathrm{BH}}$, are considered as the "master" degrees of freedom for the two frames and the others are the "slave" degrees of freedom. We define the latter as $\mathbf{X}_{\mathrm{As}}$ and $\mathbf{X}_{\mathrm{BS}}$, with

$$
\mathbf{X}_{\mathrm{AS}}=\left[\begin{array}{l}
\mathbf{X}_{\mathrm{AF}} \\
\mathbf{X}_{\mathrm{AC}}
\end{array}\right], \quad \mathbf{X}_{\mathrm{BS}}=\left[\begin{array}{l}
\mathbf{X}_{\mathrm{BF}} \\
\mathbf{X}_{\mathrm{BC}}
\end{array}\right]
$$

It is convenient first to summarise the substructuring approach in terms of a generic system (frame A or frame B) having master and slave degrees of freedom $\mathbf{X}_{H}$ and $\mathbf{X}_{S}$ respectively. The mass and stiffness matrices for the generic system are $\mathbf{M}$ and $\mathbf{K}$, which are partitioned in accordance with the definition of masters and slaves. The equations of motion may then be expressed in the partitioned form

$$
\left[\begin{array}{l}
\mathbf{M}_{\mathrm{HH}} \mathbf{M}_{\mathrm{HS}} \\
\mathbf{M}_{\mathrm{HS}}{ }^{\mathrm{T}} \mathbf{M}_{\mathrm{SS}}
\end{array}\right]\left[\begin{array}{c}
\ddot{\mathbf{X}}_{\mathrm{H}} \\
\ddot{\mathbf{X}}_{\mathrm{S}}
\end{array}\right]+\left[\begin{array}{c}
\mathbf{K}_{\mathrm{HH}} \mathbf{K}_{\mathrm{HS}} \\
\mathbf{K}_{\mathrm{HS}}{ }^{\mathrm{T}} \mathbf{K}_{\mathrm{SS}}
\end{array}\right]\left[\begin{array}{l}
\mathbf{X}_{\mathrm{H}} \\
\mathbf{X}_{\mathrm{S}}
\end{array}\right]=\left[\begin{array}{c}
\mathbf{F}_{\mathrm{H}} \\
\mathbf{F}_{\mathrm{S}}
\end{array}\right],
$$

where ${ }^{\mathrm{T}}$ denotes transpose and at this point damping forces are neglected. Using the approximation of static condensation, we impose the condition that the displacements in the slave degrees of freedom are related to the masters by a quasistatic dependency: the overall loads transmitted may be dynamic, but they are treated as being quasistatic and do not excite responses in the local vibration modes of the structural members connecting the master and slave nodes. The degrees of freedom are therefore assumed to be constrained by the relationship

$$
\mathbf{K}_{\mathrm{HS}}^{\mathrm{T}} \mathbf{X}_{\mathrm{H}}+\mathbf{K}_{\mathrm{SS}} \mathbf{X}_{\mathrm{S}}=\mathbf{0}
$$

It is convenient to write this in terms of a transformation matrix

$$
\mathbf{X}=\left[\begin{array}{c}
\mathbf{X}_{\mathrm{H}} \\
\mathbf{X}_{\mathrm{S}}
\end{array}\right]=\left[\begin{array}{c}
\mathbf{I} \\
-\mathbf{K}_{\mathrm{SS}}{ }^{-1} \mathbf{K}_{\mathrm{HS}}^{\mathrm{T}}
\end{array}\right] \mathbf{X}_{\mathrm{H}}=\left[\begin{array}{c}
\mathbf{I} \\
\mathbf{T}_{\mathrm{SH}}
\end{array}\right] \mathbf{X}_{\mathrm{H}} .
$$

Substitution of Eq. (4) into Eq. (2), pre-multiplication by the transpose of the transformation matrix, and expansion of the resulting equation leads (Przemieniecki, 1985; Sun et al., 2012) to

$$
\left[\mathbf{M}_{\mathrm{HH}}+\mathbf{M}_{\mathrm{HS}} \mathbf{T}_{\mathrm{SH}}+\mathbf{T}_{\mathrm{SH}}^{\mathrm{T}} \mathbf{M}_{\mathrm{HS}}^{\mathrm{T}}+\mathbf{T}_{\mathrm{SH}}^{\mathrm{T}} \mathbf{M}_{\mathrm{SS}} \mathbf{T}_{\mathrm{SH}}\right] \ddot{\mathbf{X}}_{\mathrm{H}}+\left[\mathbf{K}_{\mathrm{HH}}+\mathbf{K}_{\mathrm{HS}} \mathbf{T}_{\mathrm{SH}}\right] \mathbf{X}_{\mathrm{H}}=\mathbf{F}_{\mathrm{H}}+\mathbf{T}_{\mathrm{SH}}^{\mathrm{T}} \mathbf{F}_{\mathrm{S}}
$$


Eq. (5) may be written more compactly as

$$
\mathbf{M}_{\mathrm{HH}}^{*} \ddot{\mathbf{X}}_{\mathrm{H}}+\mathbf{K}_{\mathrm{HH}}^{*} \mathbf{X}_{\mathrm{H}}=\mathbf{F}_{\mathrm{H}}^{*}
$$

where

$$
\begin{aligned}
& \mathbf{M}_{\mathrm{HH}}^{*}=\mathbf{M}_{\mathrm{HH}}+\mathbf{M}_{\mathrm{HS}} \mathbf{T}_{\mathrm{SH}}+\mathbf{T}_{\mathrm{SH}}^{\mathrm{T}} \mathbf{M}_{\mathrm{HS}}^{\mathrm{T}}+\mathbf{T}_{\mathrm{SH}}^{\mathrm{T}} \mathbf{M}_{\mathrm{SS}} \mathbf{T}_{\mathrm{SH}}, \\
& \mathbf{K}_{\mathrm{HH}}^{*}=\mathbf{K}_{\mathrm{HH}}+\mathbf{K}_{\mathrm{HS}} \mathbf{T}_{\mathrm{SH}}, \\
& \mathbf{F}_{\mathrm{H}}^{*}=\mathbf{F}_{\mathrm{H}}+\mathbf{T}_{\mathrm{SH}}^{\mathrm{T}} \mathbf{F}_{\mathrm{S}} .
\end{aligned}
$$

The simpler form of Eq. (7b) compared with Eq. (7a) results from the constraint given in Eq. (4). It may be seen, however, that the inertial loads associated with the slave degrees of freedom appear in Eq. (7a), via the terms $\mathbf{M}_{\mathrm{SS}}$ and $\mathbf{M}_{\mathrm{HS}}$. Eq. (7c) expresses the static equivalence of any loads on the slave degrees of freedom (in this case the wave loads on the floats).

Eq. (6) has been obtained by substructuring a generic system. We now assume that this approach is adopted for both of the frames A and B described above, with their associated master degrees of freedom $\mathbf{X}_{\mathrm{AH}}$ and $\mathbf{X}_{\mathrm{BH}}$. It may be recalled that in a three dimensional model these would be the six degrees of freedom of the joint which is common to frames $A$ and $B$. The matrices resulting from the substructuring procedure, $\mathbf{M}_{\mathrm{HH}}^{*}$ etc. for each frame, are now written as $\mathbf{M}_{\mathrm{A}}, \mathbf{M}_{\mathrm{B}}, \mathbf{K}_{\mathrm{A}}, \mathbf{K}_{\mathrm{B}}$, with the load vectors $\mathbf{F}_{\mathrm{AH}}, \mathbf{F}_{\mathrm{BH}}$. We then simplify the model, and the description of the methodology, by assuming that the system responds only in a vertical plane. The degrees of freedom in frame $\mathrm{A}$ at the hinge are horizontal displacement $\left(X_{\mathrm{H} 1}\right)$, vertical displacement $\left(X_{\mathrm{H} 2}\right)$ and rotation $\left(X_{\mathrm{H} 3}\right)$ about the axis perpendicular to the displacements; and similarly $X_{\mathrm{H} 4}, X_{\mathrm{H} 5}$ and $X_{\mathrm{H} 6}$ for the degrees of freedom corresponding to frame $B$.

The next stage of writing the equations of motion for the overall model is to impose the conditions that the translational degrees of freedom in the two frames at the hinge are rigidly connected, so that $X_{\mathrm{H} 1}=X_{\mathrm{H} 4}, X_{\mathrm{H} 2}=X_{\mathrm{H} 5}$. Furthermore, the rotational degrees of freedom $X_{\mathrm{H} 3}=X_{\mathrm{H} 6}$ are connected by the PTO. We can write the PTO equation in the form

$$
N=B_{\text {PTO }} \mathrm{D}\left(X_{\mathrm{H} 3}-X_{\mathrm{H} 6}\right) \text {, }
$$

where $N$ is the moment transmitted into the PTO system, $B_{\text {PTO }}$ is a system dependent coefficient (e.g. a damping coefficient) and $\mathrm{D}(\mathrm{)})$ is a differential operator (e.g. a time derivative) if the PTO is modelled as a simple damper. In this case the PTO reacts against the relative rotations of the two frames at their connecting point.

These constraints may be incorporated into the equations of motion expressed in terms of the hinge degrees of freedom by writing them in the form

$$
\mathbf{M}_{\mathrm{H}} \ddot{\mathbf{X}}_{\mathrm{H}}+\mathbf{K}_{\mathrm{H}} \mathbf{X}_{\mathrm{H}}=\mathbf{F}_{\mathrm{H}},
$$

where

$$
\begin{aligned}
\mathbf{M}_{\mathrm{H}} & =\left[\begin{array}{c}
{\left[\mathbf{M}_{\mathrm{A}}\right]\left[\mathbf{0}_{3 \times 3}\right]\left[\mathbf{0}_{3 \times 2}\right]} \\
{\left[\mathbf{0}_{3 \times 3}\right]\left[\mathbf{M}_{\mathrm{B}}\right]\left[\mathbf{0}_{3 \times 2}\right]} \\
{\left[\mathbf{0}_{3 \times 3}\right]\left[\mathbf{0}_{3 \times 3}\right]\left[\mathbf{0}_{2 \times 2}\right]}
\end{array}\right], \\
\mathbf{K}_{\mathrm{H}} & =\left[\begin{array}{cccccccc}
K_{\mathrm{A} 11} & K_{\mathrm{A} 12} & K_{\mathrm{A} 13} & 0 & 0 & 0 & 1 & 0 \\
K_{\mathrm{A} 21} & K_{\mathrm{A} 22} & K_{\mathrm{A} 23} & 0 & 0 & 0 & 0 & 1 \\
K_{\mathrm{A} 31} & K_{\mathrm{A} 32} & K_{\mathrm{A} 33}+B_{\mathrm{PTO}} D & 0 & 0 & -B_{\mathrm{PTO}} D & 0 & 0 \\
0 & 0 & 0 & K_{\mathrm{B} 11} & K_{\mathrm{B} 12} & K_{\mathrm{B} 13} & -1 & 0 \\
0 & 0 & 0 & K_{\mathrm{B} 21} & K_{\mathrm{B} 22} & K_{\mathrm{B} 23} & 0 & -1 \\
0 & 0 & -B_{\mathrm{PTO}} D & K_{\mathrm{B} 31} & K_{\mathrm{B} 32} & K_{\mathrm{B} 33}+B_{\mathrm{PTO}} D & 0 & 0 \\
1 & 0 & 0 & -1 & 0 & 0 & 0 & 0 \\
0 & 1 & 0 & 0 & -1 & 0 & 0 & 0
\end{array}\right], \\
\mathbf{X}_{\mathrm{H}} & =\left[\mathbf{X}_{\mathrm{AH}}^{\mathrm{T}} \mathbf{X}_{\mathrm{BH}}^{\mathrm{T}} 00\right]^{\mathrm{T}}, \\
\mathbf{F}_{\mathrm{H}} & =\left[\mathbf{F}_{\mathrm{AH}}^{\mathrm{T}} \mathbf{F}_{\mathrm{BH}}^{\mathrm{T}} T_{1} T_{2}\right]^{\mathrm{T}},
\end{aligned}
$$

where $T_{1}$ and $T_{2}$ are the internal forces in the horizontal and vertical directions transmitted through the hinge joint. The terms in the matrix $\mathbf{K}_{\mathrm{H}}$ and in the force vector $\mathbf{F}_{\mathrm{H}}$ may be confirmed by direct inspection, or derived formally by the use of Lagrange multipliers in a similar manner to that used by Sun et al. (2011).

In principle, solution of the equations of motion (9) provides a direct means of obtaining the PTO moment. Backsubstitution of the solutions $\mathbf{X}_{\mathrm{H}}$ leads to the motions of the floats, $\mathbf{X}_{\mathrm{AF}}$ and $\mathbf{X}_{\mathrm{BF}}$. If required, the solutions for displacements $\mathbf{X}_{\mathrm{AS}}$ and $\mathbf{X}_{\mathrm{BS}}$ in the slave degrees of freedom can be used in a member by member analysis of the member end forces, leading to local stresses. All of this presupposes, however, that the fluid loading has been suitably incorporated into the analysis. It is 
convenient to consider separately hydrodynamic loading due to wave diffraction and radiation effects; hydrostatics; and drag damping. These are discussed next.

\subsection{Hydrodynamic loading}

Linear potential flow theory is assumed to provide a satisfactory model of the hydrodynamics, adapted with extra terms to approximate some effects of viscous drag. It is convenient first to consider excitation by a linear sinusoidal wave. In a general three dimensional (3D) analysis this would lead to three diffraction forces and three moments, in addition to $6 \times 6$ added mass and radiation damping matrices for each float, associated with the float degrees of freedom $\mathbf{X}_{\mathrm{AF}}$ and $\mathbf{X}_{\mathrm{BF}}$. Usually these are obtained using general purpose diffraction-radiation programs, such as WAMIT (e.g. Lee and Newman, 1991) or DIFFRACT (e.g. Sun et al., 2010). Such codes can allow all hydrodynamic coupling effects between closely spaced bodies to be calculated (for example an added mass term coupling the surge response of one float with the pitch response of a neighbouring float). For the results obtained here, however, we have used a simpler approach: the system responds in a vertical plane (as explained above); and hydrodynamic coupling between bodies is ignored. It is expected that the latter assumption may be not unreasonable, since the floats are intended to be in the inertia regime (diameter $<$ wavelength/5), so diffraction effects will be small. Furthermore, the submerged geometry of each float under investigation here is axisymmetric about a vertical axis.

These considerations lead to the use of an axisymmetric hydrodynamic analysis tool. We use the program AXID, based on coupling a finite element model of the flow field near the axisymmetric body, and an eigenfunction series expansion in the far field. The methodology was implemented by Hung (1981) and is very similar to that described by Eatock Taylor and Zietsman (1981) for the planar two dimensional diffraction-radiation problem. It has been extensively validated by comparing results for truncated cylinders with other published results obtained by various alternative methods. For example, Fig. 3 shows some results for a truncated cylinder of radius $a$, draft $a / 2$, in water of depth $1.5 a$, plotted against wavenumber $k$ multiplied by $a$. The finite element mesh used to obtain the results is formed of quadratic isoparametric elements, as shown in Fig. 3a. The heave force computed by AXID in Fig. $3 \mathrm{~b}$, non-dimensionalised by $\pi \rho g a^{2} A$, is compared with equivalent results obtained by Garrett (1971) using an eigenfunction expansion analysis. Here $\rho$ is the density of water, $g$ is the acceleration due to gravity, and $A$ is the amplitude of the incident wave. The added mass in Fig. $3 c$ non-dimensionalised by $\pi g a^{3}$, and the added damping in Fig. 3d by $\pi g a^{3} \omega$ where $\omega$ is the frequency, are compared with results obtained using the expressions given by Yeung (1981) for truncated cylinders. Some published comparisons with a nonlinear boundary element analysis are given by Eatock Taylor et al. (2009).

(a)
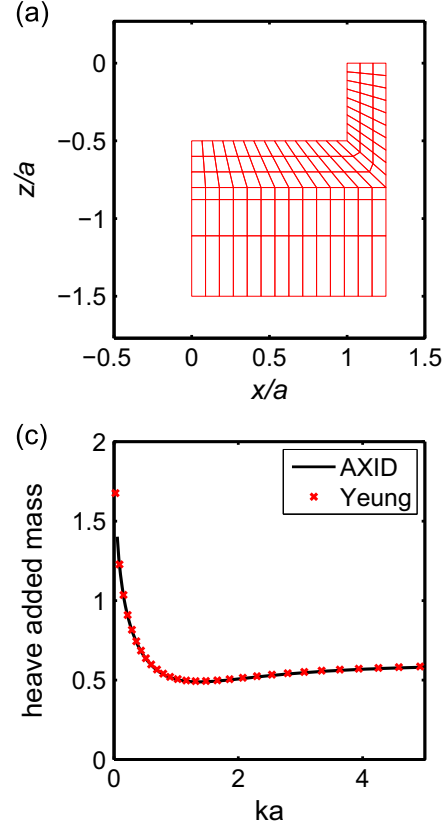

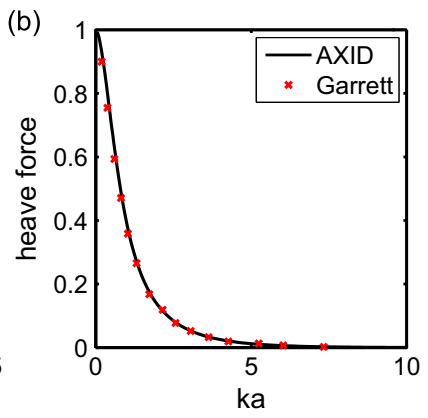

(d)

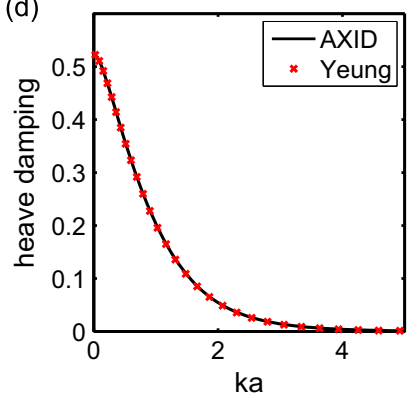

Fig. 3. Validation of axisymmetric diffraction analysis AXID with results of Garrett (1971) and Yeung (1981). (a) Finite element mesh; (b) dimensionless heave force; (c) dimensionless heave added mass; (d) dimensionless heave damping. 


\subsection{Incorporation of additional effects due to hydrostatics and distributed inertia}

Hydrostatic stiffness terms are associated with the vertical and rotational motions of the floats. These are attributed to the nodes of the frames which are located on the axis of each float at the still water level. The complete system is freely floating, so its total weight is supported by the displaced volumes of the floats. Thus the weight supported by each float is known, which provides a contribution to the restoring moment opposite to the restoring effect from the moment of the water plane area, as in a standard calculation for an isolated float using the metacentric height. One other stiffness effect should also be mentioned, arising from any moorings needed to keep the system on station. It is assumed here that the influence of such a mooring system on the responses at wave frequencies would be negligible; in the experiments the device was kept in position by a light string attached to the bow float.

The inertias of the structural elements in the frames are accounted for directly in the matrix M discussed above. Additional mass and moments of inertia of each float, ballast and PTO etc. must also be incorporated. For the device analysed here these have been evaluated as a set of point masses at specified positions, and moments of inertia of the complete system about the hinge point. The point masses are attributed to the nearest structural nodes, and thereby included in $\mathbf{M}$. The moments of inertia are attributed to the rotational degrees of freedom at the hinge. The substructuring procedure accounts for terms such as $m_{i} \ddot{X}_{\mathrm{S} 1}^{i}, m_{i} x_{i} \ddot{X}_{\mathrm{S} 2}^{i}, m_{i} x_{i}{ }^{2} \ddot{X}_{\mathrm{S} 3}^{i}$, in the appropriate translational and rotational equations of motion in terms of the horizontal, vertical and rotational slave degrees of freedom $\mathbf{X}_{\mathrm{S}}$ associated with node $i$, where $m_{i}$ is a typical mass at a point with horizontal location $x_{i}$ (with analogous terms involving vertical coordinates $z_{i}$ ). But as contributions such as the third term $m_{i} x_{i}{ }^{2} \ddot{X}_{\mathrm{AH} 3}^{i}$ have already been included in the global moments of inertia referred to above, these terms must be subtracted out of the system Eq. (10) to avoid double counting.

\subsection{Representation of drag damping}

Design of a wave energy converter of the type under consideration here implies the need to model reliably the behaviour at resonance, and therefore to include in the analysis all significant forms of damping. One source is the radiation damping due to wave making, which is part of the output of the potential flow analysis. Another, also expected to be important, is the drag damping associated with viscous effects, particularly if the floats have sharp corners which may lead to the shedding of eddies. Here we assume that the drag damping may be represented by a velocity squared effect, with some prescribed drag coefficient. The problem is that drag is due to heave and surge, and possibly pitch motion; not just simple heave. The separated flow is complex, but here we investigate it using a simple approximation. In surge we write the drag force on a float of diameter $2 a$ and draft $d$ (for example float 1 ) as

$$
F_{\mathrm{AF} 1}^{\mathrm{D}}=-C_{\mathrm{D}}^{\mathrm{H}} \rho a d \dot{X}_{\mathrm{AF} 1}\left|\dot{X}_{\mathrm{AF} 1}\right|,
$$

where $C_{\mathrm{D}}^{\mathrm{H}}$ is a drag coefficient associated with horizontal motions. The moment of this force leads to $F_{\mathrm{AF} 3}^{\mathrm{D}}$. In heave we take

$$
F_{\mathrm{AF} 2}^{\mathrm{D}}=-\frac{1}{2} C_{\mathrm{D}}^{\mathrm{V}} \rho \pi a^{2} \dot{X}_{\mathrm{AF} 2}\left|\dot{X}_{\mathrm{AF} 2}\right|,
$$

using a drag coefficient $C_{\mathrm{D}}^{\mathrm{V}}$ for vertical motions.

We next approximate these forces by an equivalent linearization procedure, which is illustrated here for the case of surge force. Consider the response to regular wave excitation of period $T$ and frequency $\omega$ with a linearised drag force given by

$$
\bar{F}_{\mathrm{AF} 1}^{\mathrm{D}}=-b \dot{X}_{\mathrm{AF} 1} \text {. }
$$

The coefficient $b$ is obtained by minimising the mean squared error in the approximation over one cycle, which leads to

$$
b=C_{\mathrm{D}}{ }^{\mathrm{H}} \rho \mathrm{ad} \int_{0}^{T} \dot{X}_{\mathrm{AF} 1}{ }^{2}\left|\dot{X}_{\mathrm{AF} 1}\right| d t / \int_{0}^{T} \dot{X}_{\mathrm{AF} 1}^{2} d t=\frac{8}{3 \pi} C_{\mathrm{D}}{ }^{\mathrm{H}} \rho a d \dot{X}_{\mathrm{AF} 1}^{0},
$$

where the superscript 0 indicates the amplitude of the sinusoidally varying quantity (here surge velocity). Clearly this requires the solution to be obtained iteratively, since $\dot{X}_{\mathrm{AF} 1}^{0}$ is not known until the equations of motion have been solved. In practice it has been found that the iteration converges after a very small number of iterations (up to 5), using the same approach in each iteration for all of the drag forces.

A similar approach may be adopted in order to estimate the drag forces when the system responds to random waves. In this case the unknown coefficient $b$ is obtained by minimising the expected value of the mean square error. This leads (see for example Krylov and Bogoliubov (1943) and Malhotra and Penzien (1970)) to

$$
b=C_{\mathrm{D}}{ }^{\mathrm{H}} \rho a d \frac{E\left[\dot{X}_{\mathrm{AF} 1}{ }^{2}\left|\dot{X}_{\mathrm{AF} 1}\right|\right]}{E\left[\dot{X}_{\mathrm{AF} 1}{ }^{2}\right]}=\sqrt{\frac{8}{\pi}} C_{\mathrm{D}}{ }^{\mathrm{H}} \rho a d \sigma_{\mathrm{u} 1},
$$

where $\sigma_{\mathrm{u} 1}$ is the variance of the response velocity $\dot{X}_{\mathrm{AF} 1}$, assumed to be a Gaussian process. Again iteration is required, as explained in Section 2.6.

A slight modification to this approach, both in regular and random waves, is to model the drag force in terms of the relative velocity between the float and the fluid particle (rather than just the float velocity). Considering the vertical motions of float 1 , for example, let us assume that a representative vertical wave particle velocity is defined as $\dot{U}_{\mathrm{AF} 2}$ corresponding to 
the float vertical velocity $\dot{X}_{\mathrm{AF} 2}$ in Eq. (11b). Then the relative velocity is

$$
\dot{R}_{\mathrm{AF} 2}=\dot{X}_{\mathrm{AF} 2}-\dot{U}_{\mathrm{AF} 2} ;
$$

and the corresponding drag force becomes

$$
F_{\mathrm{AF} 2}^{\mathrm{D}}=-\frac{1}{2} C_{\mathrm{D}}^{\mathrm{V}} \rho \pi a^{2} \dot{R}_{\mathrm{AF} 2}\left|\dot{R}_{\mathrm{AF} 2}\right| .
$$

It is convenient to consider a sinusoidal oscillation at frequency $\omega$, and to work with relative displacement $R$ rather than velocity. This is of the form

$$
R=X^{0} \sin \left(\omega t+\epsilon_{1}\right)-U^{0} \sin \left(\omega t+\epsilon_{2}\right),
$$

where $\varepsilon_{1}$ and $\varepsilon_{2}$ are phase angles. This may be written

$$
R=R^{0} \sin \left(\omega t+\epsilon_{3}\right)
$$

where

$$
R^{0}=\left[U^{2}+X^{2}-2 U X \cos \left(\epsilon_{1}-\epsilon_{2}\right)\right]^{\frac{1}{2}}
$$

and the phase angle $\varepsilon_{3}$ is immaterial when the integrations are done for the linearization.

This linearization may be undertaken as before, leading to an equivalent coefficient in regular waves

$$
b=\frac{4}{3} C_{\mathrm{D}}^{\mathrm{V}} \rho a^{2} \dot{R}_{\mathrm{AF} 2}^{0}
$$

It may be shown that in random waves the equivalent coefficient is

$$
b=\sqrt{2 \pi} C_{\mathrm{D}}^{\mathrm{V}} \rho a^{2} \sigma_{\mathrm{R} 2}
$$

where $\sigma_{\mathrm{R} 2}$ is the variance of the relative velocity. The result is a modified damping term, and an additional component of the wave force on the float. (It may be noted this relative motion approach would not be appropriate if diffraction was significant, as the wave field would be modified: this effect and the effects of radiated waves on adjacent floats are assumed to be small, as the latter decay radially.) Continuing the illustration of the drag effects in the vertical degree of freedom of float 1, we obtain the additional component of wave force due to vertical drag in random waves:

$$
F_{\mathrm{AF} 2}^{\mathrm{WD}}=\sqrt{2 \pi} C_{\mathrm{D}}^{\mathrm{V}} \rho \pi a^{2} \sigma_{\mathrm{R} 2} \dot{U}_{\mathrm{AF} 2} .
$$

This and equivalent forces at the other float degrees of freedom may be simply incorporated into the load terms on the right hand sides of Eq. (9).

\subsection{Analysis of mean wave power}

The case of regular waves is discussed first. A set of initial float velocity amplitudes is assumed, so that drag coefficients and forces as given by Eqs. (18a) and (16) for regular waves may be formulated. These are incorporated into the equations of motion involving the float degrees of freedom, prior to the substructuring procedure. The added mass, damping and hydrostatic terms are included as discussed above, as well as the point masses. Eq. (10) is then formulated in terms of the displacements and rotations of the hinge, and the unknown internal forces at the hinge. The latter are not explicitly required in what follows, but their presence is implicit in the method of analysis presented. Once these equations of motion have been solved in the frequency domain, back-substitution yields the amplitudes of the float displacements, from which the equivalent linearised drag force coefficients $b$ may be updated. The whole procedure is repeated until the results have suitably converged. The moment $N$ transmitted into the PTO system can then be obtained from Eq. (8), and for the case of a PTO represented by a linear damper the mean power in regular waves of frequency $\omega$ is given by

$$
P=\frac{1}{2} \omega^{2} B_{\text {РTO }}\left(\theta^{0}\right)^{2}
$$

Here $\theta^{0}$ is the amplitude of the relative rotation of the PTO element, namely $\left(X_{\mathrm{AH} 3}-X_{\mathrm{BH} 3}\right)$.

The analysis of mean power in irregular waves is only slightly more complicated. For our model involving motions of the device in a vertical plane we consider unidirectional waves whose crests are perpendicular to that plane. The one-sided spectral density of wave elevation is taken to be $S(\omega)$. Similarly to the iterative approach in regular waves, the equations of motion are first solved with assumed drag damping terms, based now on an initial set of velocity response variances, $\sigma_{\mathrm{u}}$. The linearised equations of motion are solved in the frequency domain, as described at the start of this section. Frequency response functions are thereby obtained, say $H(\omega)$ (a complex function) for a typical float displacement excited by a wave of unit amplitude. The spectrum of relative velocity $u$ is then given by

$$
S_{\mathrm{uu}}(\omega)=\omega^{2}|H(\omega)|^{2} S(\omega),
$$


and the relative velocity variance is

$$
\sigma_{u}=\left[\int_{0}^{\infty} \omega^{2}|H(\omega)|^{2} S(\omega) \mathrm{d} \omega\right]^{\frac{1}{2}} .
$$

From this result the linearised force drag coefficients such as $b$ in Eq. (18b) are obtained, and the iteration repeated. The iteration cycle is again found to converge fast, after which the complex frequency response function $\Theta(\omega)$ for the PTO rotation is derived. This leads directly to the mean power expressed as

$$
P=B_{\text {PTO }} \int_{0}^{\infty} \omega^{2}|\Theta(\omega)|^{2} S(\omega) d \omega \text {. }
$$

\subsection{Capture width}

In regular waves of amplitude $A$, the mean incident power per unit width of wave front is (e.g. Falnes, 2007)

$$
P_{\mathrm{I}}=\frac{1}{2} \rho g A^{2} c_{\mathrm{g}}
$$

where $c_{\mathrm{g}}$ is the group velocity of the wave whose frequency is $\omega$ and wavenumber $k$. In water of depth $h$, the group velocity is

$$
c_{\mathrm{g}}=\frac{\omega}{2 k}[1+2 k h / \sinh (2 k h)]
$$

It useful to express the theoretical power absorption capability of a wave energy converter in terms of the capture width (e.g. Babarit, 2015). This can be defined as the length of an incident wave front which transports the same mean power flux as is absorbed by the device; it has the units of length. The capture width ratio is here defined as the capture width nondimensionalised by the wave length, $\lambda$. The capture width ratio is therefore expressed by

$$
\kappa=\frac{P}{\lambda P_{I}} \text {. }
$$

To put this parameter in context (and the results given below), one may consider a result obtained by Evans (1976) and Newman (1976): for any axisymmetric device in heave, the theoretical optimum capture width ratio is $1 / 2 \pi$. This optimum value corresponds to free motions at the heave resonant frequency or under optimal reactive control. The corresponding result for such a device in resonant pitch motions is $1 / \pi$. But in practice the associated responses may exceed the capability of such a device (and the limits of linear theory). It should also be noted that this definition differs from that used by some investigators, and the one used in the database of Babarit (2015), where the non-dimensionalisation length is characteristic body dimension rather than wave length, and the figures presented are annual averages.

In irregular waves, the mean incident power per unit width of wave front is

$$
P_{\mathrm{I}}=\rho g \int_{0}^{\infty} S(\omega) c_{\mathrm{g}} d \omega
$$

with $c_{\mathrm{g}}$ given by Eq. (25). This is sometimes written in the form

$$
P_{\mathrm{I}}=\frac{1}{16} \rho g H_{\mathrm{s}}^{2} c_{\mathrm{ge}},
$$

where $H_{\mathrm{s}}$ is the significant wave height and $c_{\mathrm{ge}}$ is the group velocity corresponding to a regular wave of frequency $\omega_{\mathrm{e}}$ and period $T_{e}$, the "energy period" (Mollison et al., 1976; Cahill and Lewis, 2014). In deep water waves

$$
c_{\mathrm{g}}=\frac{\mathrm{g}}{2 \omega}
$$

Substitution of this deep water group velocity into the integral in Eq. (27) yields equivalence with Eq. (28) if $T_{\mathrm{e}}=2 \pi / \omega_{\mathrm{e}}$ where

$$
\omega_{\mathrm{e}}=\frac{m_{0}}{m_{-1}}, \quad m_{0}=\int_{0}^{\infty} S(\omega) d \omega=\frac{H_{\mathrm{s}}^{2}}{16}, \quad m_{-1}=\int_{0}^{\infty}(S(\omega) / \omega) d \omega .
$$

\section{Application to model wave energy converters}

\subsection{Model with flat ends}

The analysis described above is now applied to a scaled model of the M4 wave energy device shown in Fig. 1. The design philosophy for the device has been outlined by Stansby et al (2015a), where details of the geometry and distribution of inertias for a $1 / 8$ th scale model are also given. This was tested in the large wave basin in COAST Laboratory at the University 
of Plymouth. Data measured in those experiments are compared here with theoretical predictions for power in regular and random waves.

Fig. 4 shows the plane frame model of the frames connecting the three floats. For clarity, the vertical scale is stretched. The rigid floats are attached to flexible frames A and B at nodes A1, A2 and B1 (though in this initial investigation the frames are specified to be relatively stiff). The hinge is at the node designated A5 and B4 in the two frames respectively; but in the figure the frames are shown with a small horizontal offset. This is to facilitate illustration of the degrees of freedom corresponding to the connected joints. As explained in Section 2, these are the master degrees of freedom. The slaves comprise the three degrees of freedom at the node in each float, and the internal degrees of freedom at the other joints of the two frames. These latter joints are labelled A3 to A4 and B2 to B3 in Fig. 4. In terms of the mass matrices introduced in Eq. (2), $\mathbf{M}_{\mathrm{SS}}$ for frames A and B have dimensions $12 \times 12$ and $9 \times 9$ respectively; and similarly for the stiffness matrices $\mathbf{K}_{\mathrm{SS}}$.

The hydrodynamic quantities for each float are analysed using the axisymmetric program AXID described in Section 2. In the finite element meshes account is taken of the small radius of curvature at the bottom corner of each float as illustrated in Fig. 5a, which is for float 3, the largest. Similar meshes are used for the other floats (though with fewer elements overall because of the smaller dimensions of the floats. It should be recalled that these are quadratic isoparametric elements, so fairly coarse-looking meshes are satisfactory at the frequencies of interest here). Plots of typical hydrodynamic quantities for float 3 are shown in Fig. 5b-d plotted against wave period. These represent surge and heave force amplitudes per unit wave amplitude; surge and heave added masses; surge and heave damping.

\subsubsection{Mean power in regular waves}

Following application of the substructuring procedure described above, the responses and absorbed power in regular waves are obtained. Fig. $6 a-c$ presents the theoretical mean power generated by this device, as predicted by the theoretical numerical model described above, plotted over a range of periods. The influence of drag coefficient is shown in Fig. 6a, for a linear power take-off having damping coefficient $B_{\text {РTO }}=4500 \mathrm{~N} \mathrm{~ms}$ and in waves of height $H=0.2 \mathrm{~m}$. It appears that the drag force has a more significant influence on reducing the responses (hence power) through extra damping at resonance, than on increasing power through the excitation forces. Fig. 6b shows the influence of the PTO coefficient at one value of drag coefficient. The four values of $B_{\text {PTO }}$ span the optimum value which leads to the highest power. Fig. $6 \mathrm{c}$ indicates the dependence of power on the incident wave height. Whereas the incident mean power varies with the square of the wave

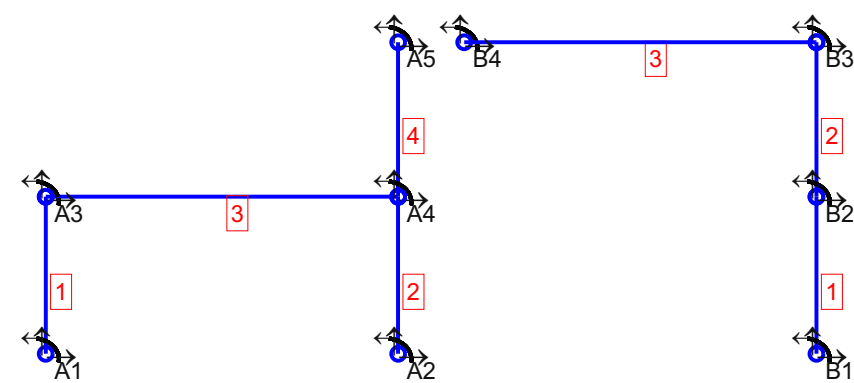

Fig. 4. Plane frame model of frames A and B attached to floats (vertical scale is stretched).

(a)

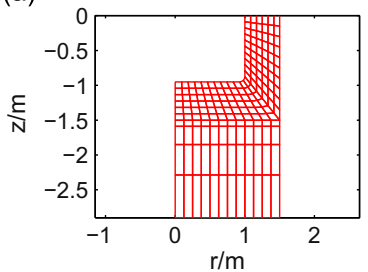

(c)

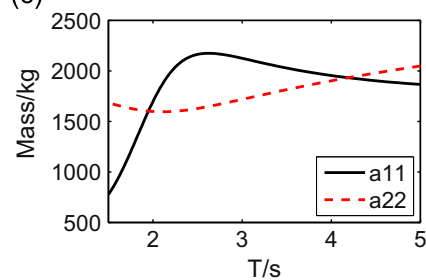

(b)

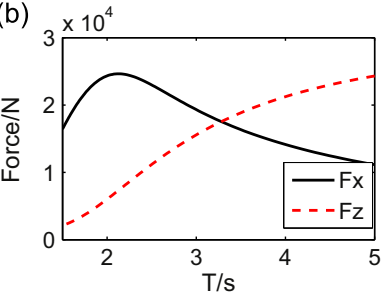

(d)

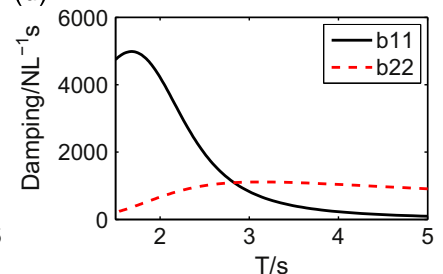

Fig. 5. Sample results of AXID analysis for float 3. (a) Finite element mesh; (b) surge and heave forces; (c) added masses in surge and heave; (d) damping in surge and heave. 

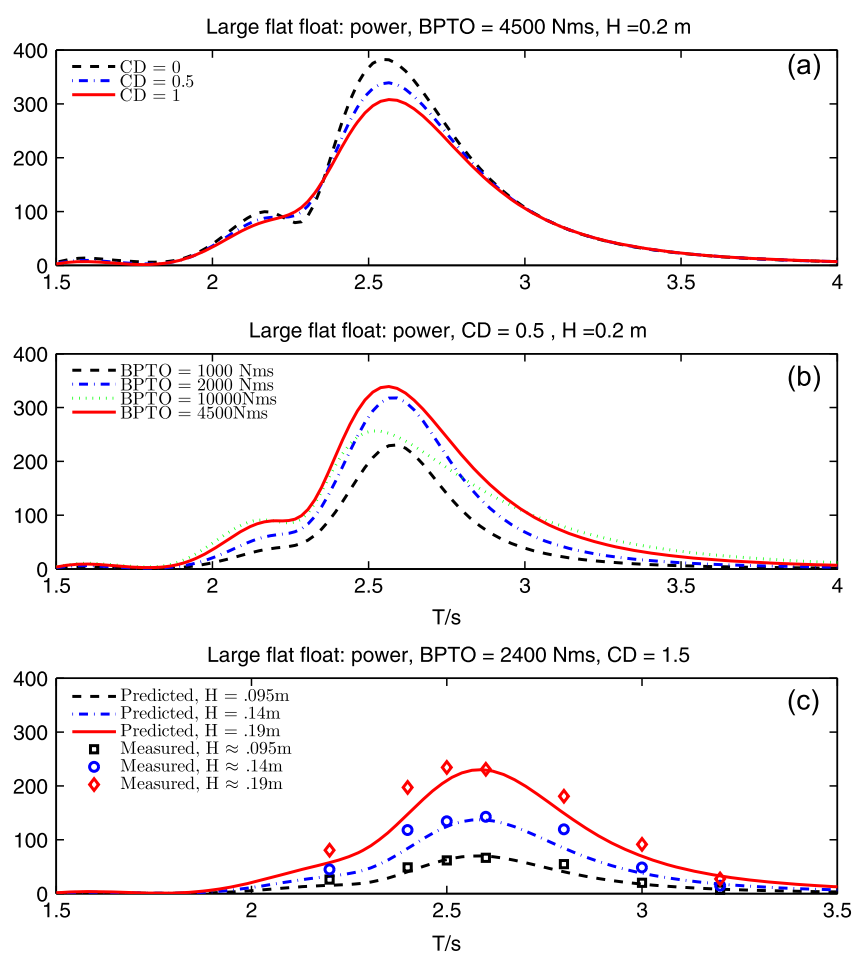

Fig. 6. Average power in regular waves under various assumptions. (a) Influence of drag coefficient; (b) influence of PTO coefficient; (c) dependence on incident wave height and comparisons with experimental data.

height, this relationship is weakened by the reduction in power caused by drag damping. The wave heights selected for the simulations were taken as the three averages of sets of experiments at seven periods and at nominally equal wave heights. The linear PTO damping coefficient was taken as $B_{\mathrm{PTO}}=2400 \mathrm{~N}$ ms, which is roughly the average of values deduced from curve fits of the corresponding forces and velocities measured in the actual PTO indicated in Fig. 1. The experimental results for mean power are also plotted in Fig. $6 \mathrm{c}$, and are seen to be close to the simulations using a drag coefficient $C_{\mathrm{D}}=1.5$.

The capture width ratios corresponding to the mean powers plotted in Fig. 6 are shown in Fig. 7. Compared with the powers, the capture width ratios are characterised by slightly more obvious secondary peaks at shorter periods than the main peak. These are somewhat masked in Fig. 6 because of the reduced incident power at the shorter periods, an effect which is removed when the output power is divided by the incident power. Fig. 7c makes clear how the capture width ratio collapses the results at different wave heights, except around the resonant peaks where the effect of drag intervenes. A discussion of the influence of the resonances, coupled with the influence of wavelength to float spacing ratio, is given in Section 3.2 (in the context of a variant of this device), following an eigen-analysis of the system.

\subsubsection{Mean power in irregular waves}

In this case it is convenient to plot mean power against peak spectral period, $T_{\mathrm{p}}$, for a given significant wave height $H_{\mathrm{s}}$. Long-crested random wave experiments on the same device were conducted at the COAST Laboratory (see Stansby et al., 2015a) for JONSWAP spectra with a peakedness factor of $\gamma=3.3$ and $T_{\mathrm{p}}$ between $2 \mathrm{~s}$ and $3.4 \mathrm{~s}$. These corresponded to three significant wave heights, given by $H_{\mathrm{s}}=0.14 \mathrm{~m}, H_{\mathrm{s}}=0.19 \mathrm{~m}$ and $H_{\mathrm{s}}=0.24 \mathrm{~m}$ (the values deduced from the wave elevation time histories were within about $5 \%$ of these values). Fig. 8a shows the experimentally determined estimates of mean power generated in these sea states, together with corresponding numerical predictions, using $B_{\mathrm{PTO}}=2400 \mathrm{~N}$ ms (taken from the experiments) and the same value $C_{\mathrm{D}}=1.5$ as in the regular wave simulations in Figs. $6 \mathrm{c}$ and $7 \mathrm{c}$. It is apparent that the simulations somewhat under-predict the experiments. The corresponding capture width ratios for this device in the same sea states are shown in Fig. 8b. Apart from one result at $T_{\mathrm{p}}=2.2 \mathrm{~s}$, the experimentally determined capture width ratios seem rather insensitive to the value of $H_{\mathrm{s}}$, as compared with Fig. 7c. This suggests that the effect of drag is rather less significant in irregular waves. This is partly because the effect of the resonant peaks in the RAOs is smeared in irregular waves.

The fit with the experimental data is considerably improved if a lower value of $C_{\mathrm{D}}$ is used for the numerical predictions, as shown in Fig. 9. In this case the discrepancies (which are more evident in the plots of capture width ratio than those of power) are only significant at the shorter periods, a little below the optimum operating conditions for the device. It is possible that hydrodynamic interaction effects are having more influence in this shorter period range. Whatever the reason, it is interesting to observe that as compared with the simple model the experiments suggest a flatter relationship between 

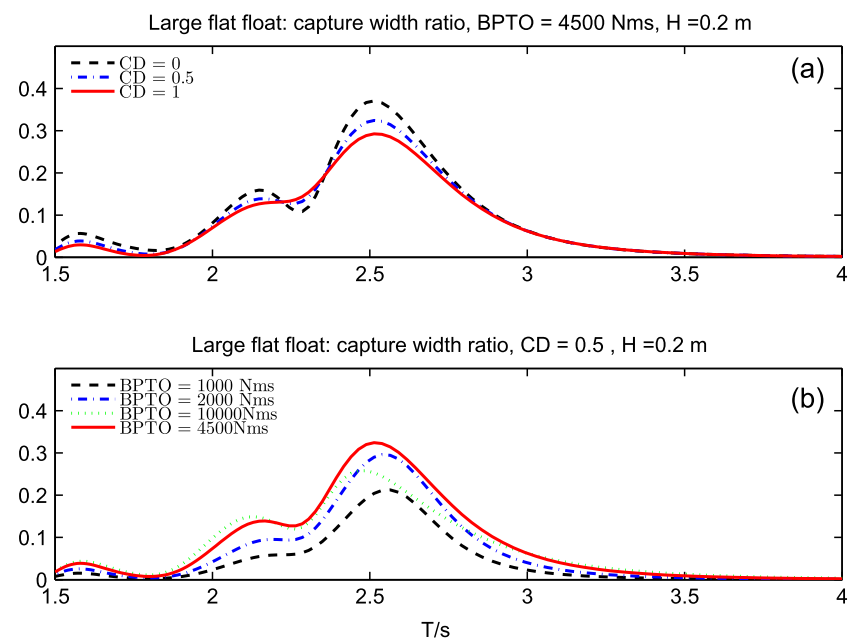

Large flat float: capture width ratio, BPTO $=2400 \mathrm{Nms}, \mathrm{CD}=1.5$

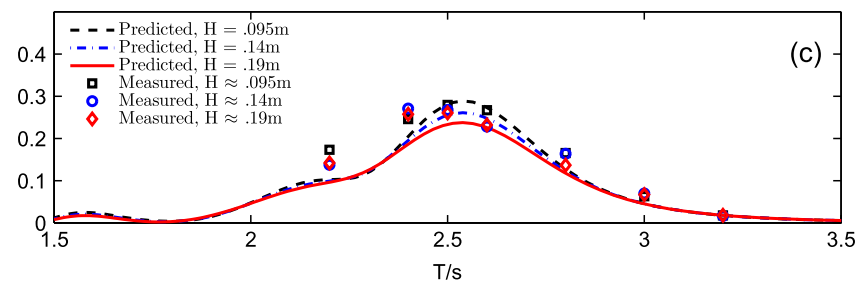

Fig. 7. Capture width ratios in regular waves. Key to (a), (b) and (c) as in Fig. 6.
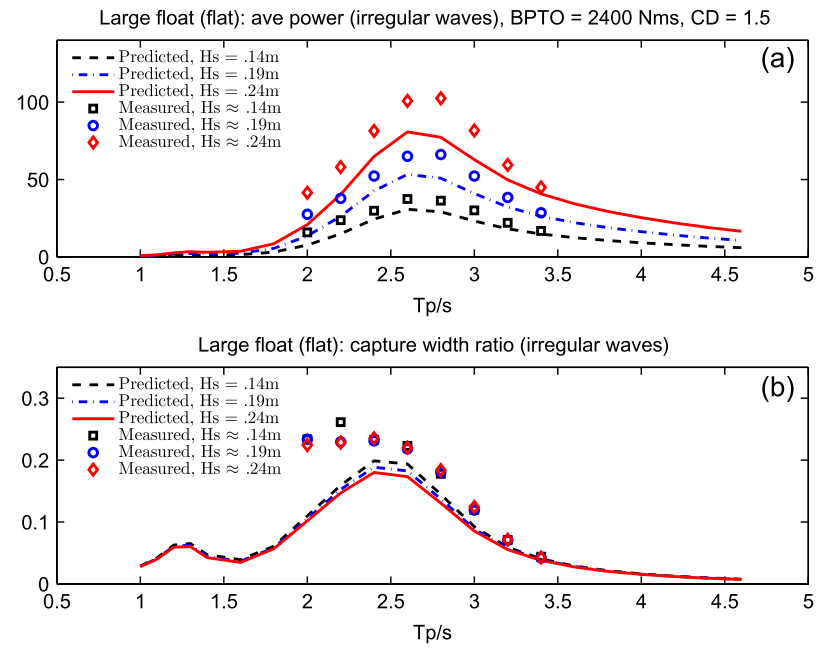

Fig. 8. Experimental data compared with model using $B P T O=2400 \mathrm{~N} \mathrm{~ms}, C_{D}=1.5$. (a) Mean power; (b) capture width ratio in irregular waves.

capture width ratio and peak period: values up to around 0.25 were obtained experimentally in irregular waves, in a device with no source of active control to optimise phasing. If this were confirmed at full scale this would clearly be beneficial.

Fitting the complex dynamics of the flow around this three float device responding in three modes, using a single drag coefficient to represent the viscous forces, is certainly simplistic, and in view of the uncertainty regarding drag coefficient it might be interesting to develop a model based on different coefficients for the three different floats and three modes of motion. Some initial work related to this has been described by Stansby et al. (2015c), covering some experiments and CFD analysis for single floats in heave. Results were obtained for floats of three different geometries (including flat and domed bases), under conditions of free decay and harmonic oscillations forced by an actuator. For the flat floats under forced oscillation, values of $C_{\mathrm{D}}$ of around 0.33 were estimated from the CFD analyses, and these are similar to the value of 0.4 used here for the flat floats in irregular waves. On this basis the anomalous value is 1.5 in regular waves. One possible reason for this relates to weak tank reflections observed in the regular wave experiments: Stansby et al. (2015a) indicate a reflection coefficient of around 7\% (which would lead to modulation of 

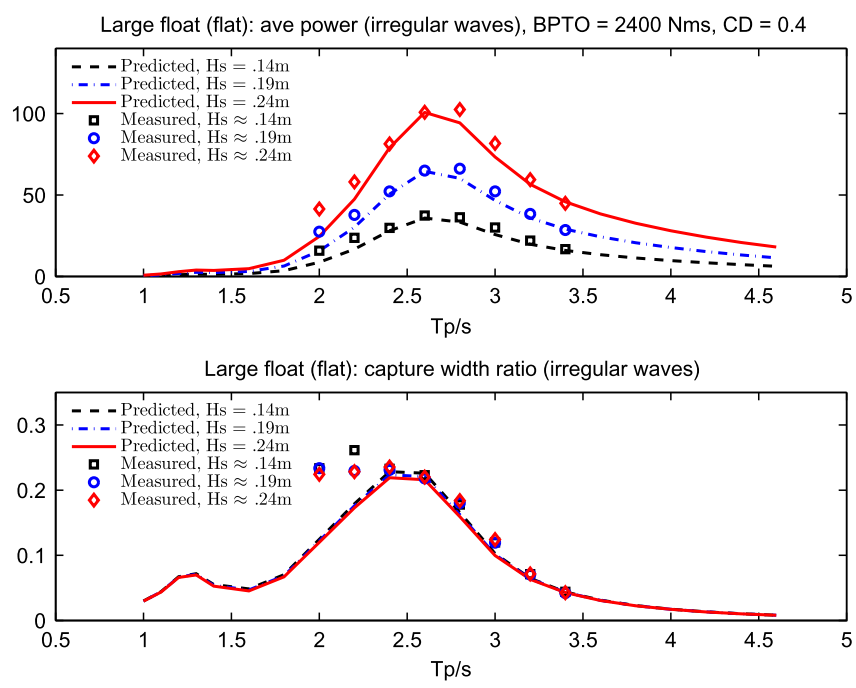

Fig. 9. As for Fig. 8, but using $C_{\mathrm{D}}=0.4$ in the model.

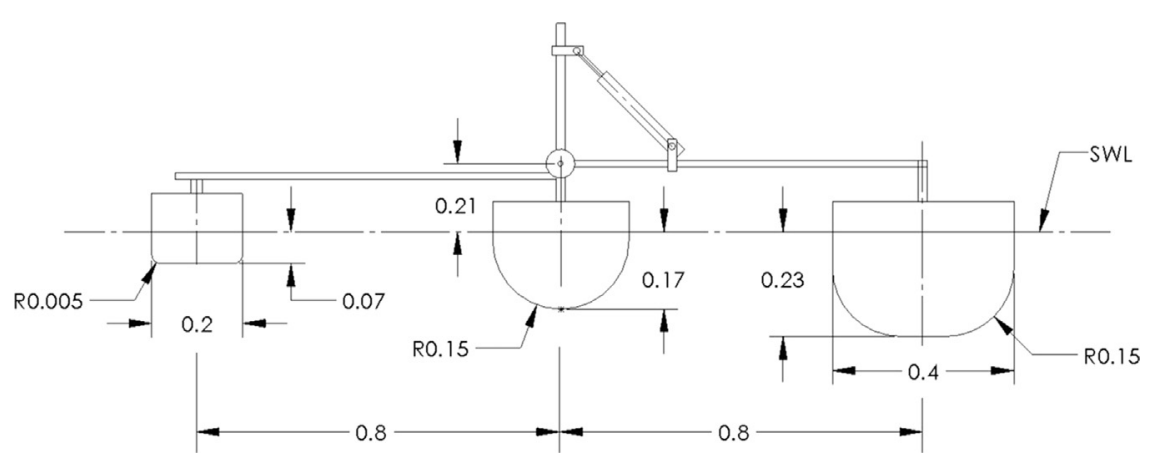

Fig. 10. Elevation of $1 / 40$ th scale model having domed ends.

Table 1

Mass distribution and inertias for domed base configuration with origin at hinge point.

\begin{tabular}{lccc}
\hline & Mass $(\mathrm{kg})$ & $x_{\mathrm{G}}(\mathrm{m})$ & $z_{\mathrm{G}}(\mathrm{m})$ \\
\hline Float 1 & 1.85 & -0.8 & -0.2 \\
Beam float 1 to 2 & 0.65 & -0.4 & -0.083 \\
Float 2 & 2.63 & 0.0 & -0.21 \\
Beam float 2 to 3 & 0.48 & 0.8 & -0.0 \\
Float 3 & 5.49 & 0.16 & -0.268 \\
Actuator & 0.19 & 0.0 & 0.16 \\
Ballast float 2 & 6.35 & 0.8 & -0.3 \\
Ballast float 3 & 19.0 & -0.15 & -0.37 \\
Combined floats 1 and 2 & 11.48 & 0.8 & -0.265 \\
Combined float 3 & 24.49 & -0.335 \\
Inertia about hinge floats 1 and 2 combined & $2.28 \mathrm{~kg} \mathrm{~m}^{2}$ & \\
Inertia about hinge float 3 & $18.81 \mathrm{~kg} \mathrm{~m}^{2}$ & & \\
\hline
\end{tabular}

$14 \%$ in power). This effect, which would not be present in the irregular wave experiments, may cause modified estimates of power which are compensated artificially by use of a higher drag coefficient.

\subsection{Model with domed ends at 1/40 scale}

The reduction of captured power due to drag damping on the flat-bottomed floats (as characterised by Figs. 6a and 7a) suggests that it might be profitable to investigate floats having more rounded corners. A modified device incorporating this idea is shown in Fig. 10, with dimensions shown for a design modelled at 1/40th of full scale. Other characteristics of this model are given in Table 1. It has been tested in long crested random waves in the wide flume at the University of 
Manchester $(5.0 \mathrm{~m}$ wide $\times 0.45 \mathrm{~m}$ deep $\times 18 \mathrm{~m}$ long). In this section we give some comparisons between experimental measurements and simulations of the measured power generated and capture width ratio, based on assuming no drag effects $\left(C_{\mathrm{D}}=0\right.$ in the numerical model). We then undertake some parametric studies, and investigate how the response of the device and power generated are linked to the dynamic behaviour, as characterised by its modes and natural frequencies, and the spacing of the floats.

As for the model with flat floats, the hydrodynamic behaviour has been evaluated with the diffraction analysis AXID. Fig. 11a shows the axisymmetric finite element mesh used for the large float. Fig. 11b-d shows the heave force amplitude, heave added mass and heave damping for this float, all plotted against wave period. The excitation and hydrodynamic damping in heave are of course directly linked by the Haskind relations (Newman, 1977).

A comparison of predictions of power and measurements in the $1 / 40$ th scale experiments in JONSWAP spectra $(\gamma=3.3)$ is given in Fig. 12. The data cover a range of peak periods, at two significant wave heights (nominally $H_{\mathrm{s}}=0.02 \mathrm{~m}$ and $H_{\mathrm{s}}=0.04 \mathrm{~m}$ ). Fig. $12 \mathrm{a}$

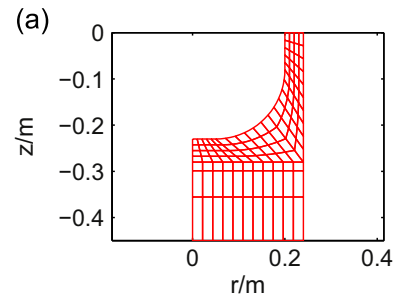

(c)

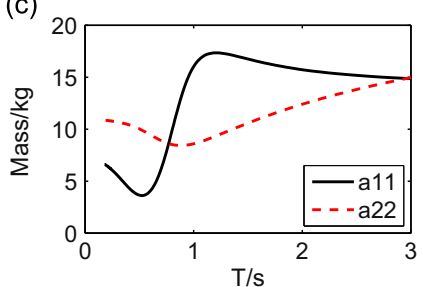

(b)

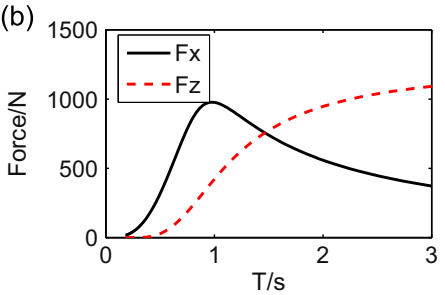

(d)

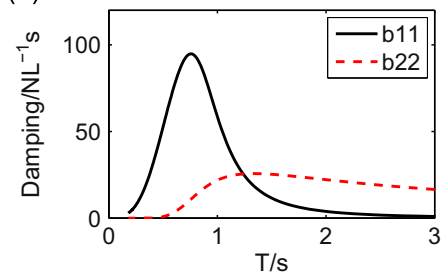

Fig. 11. Sample results of AXID analysis for float 3 of 1/40th scale model. (a) Finite element mesh; (b) surge and heave forces; (c) added masses in surge and heave; (d) damping in surge and heave.

Small float (domed): ave power (irregular waves), $C D=0$

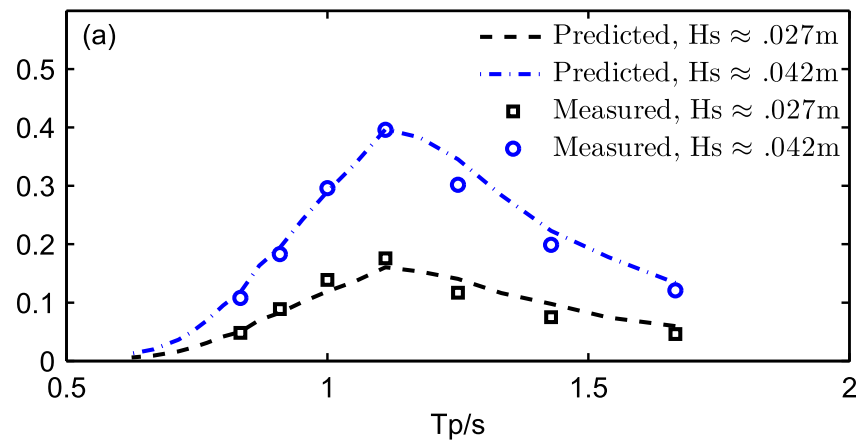

Small float (domed): capture width ratio (irregular waves)

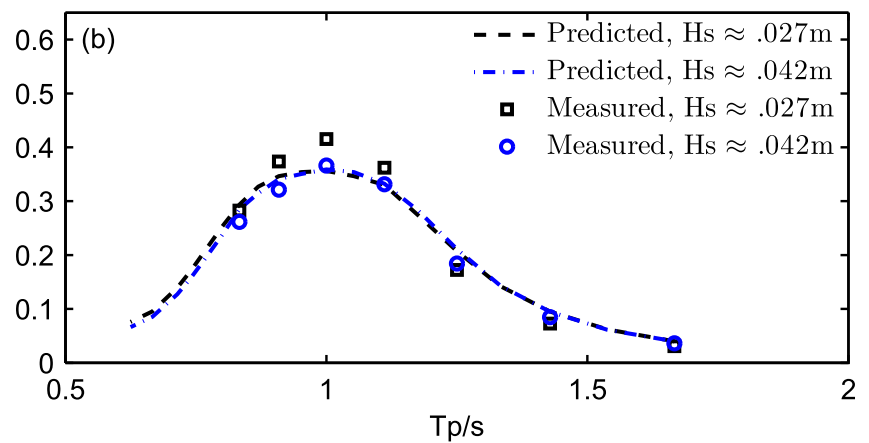

Fig. 12. Comparisons with experiments on $1 / 40$ th scale domed model in irregular waves. (a) Average power; (b) capture width ratio. 
(a)

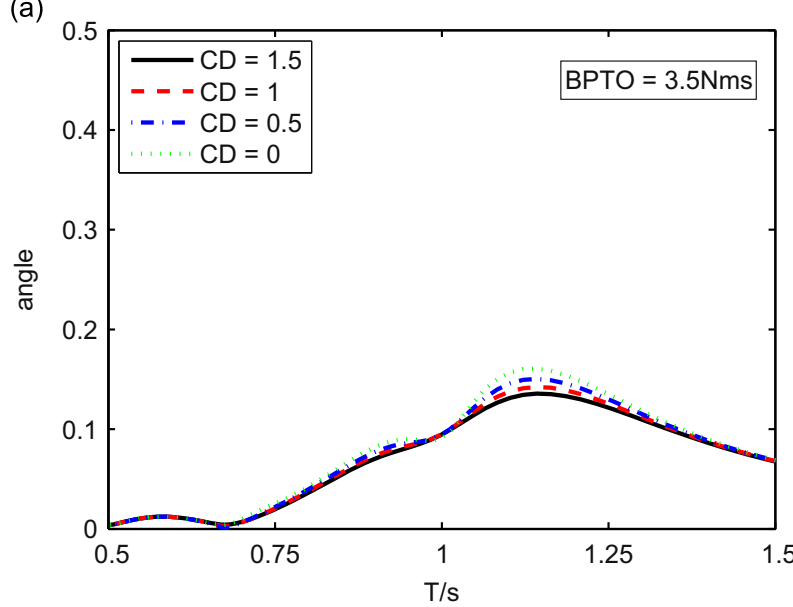

(b)

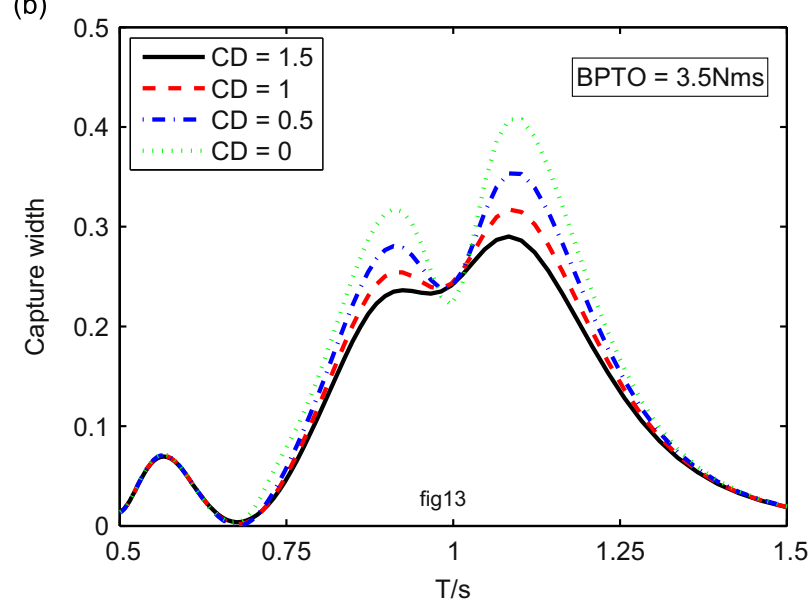

(c)

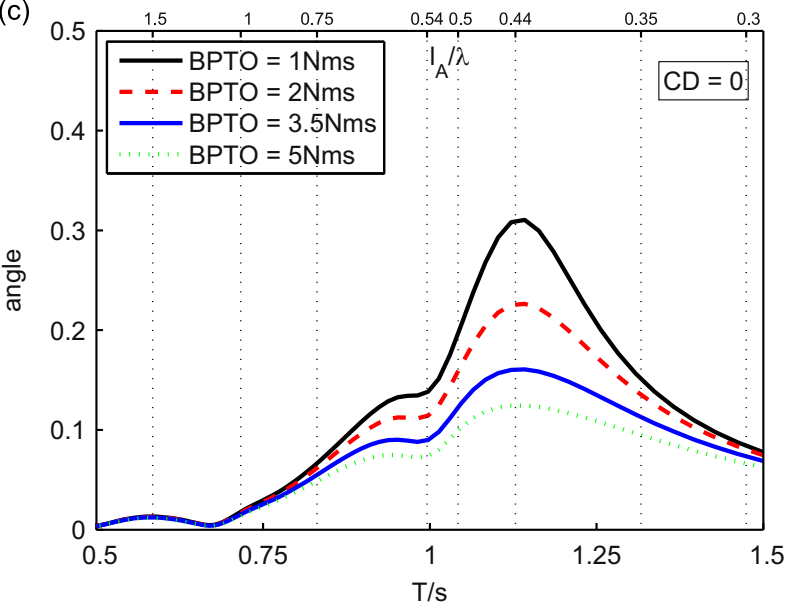

(d)

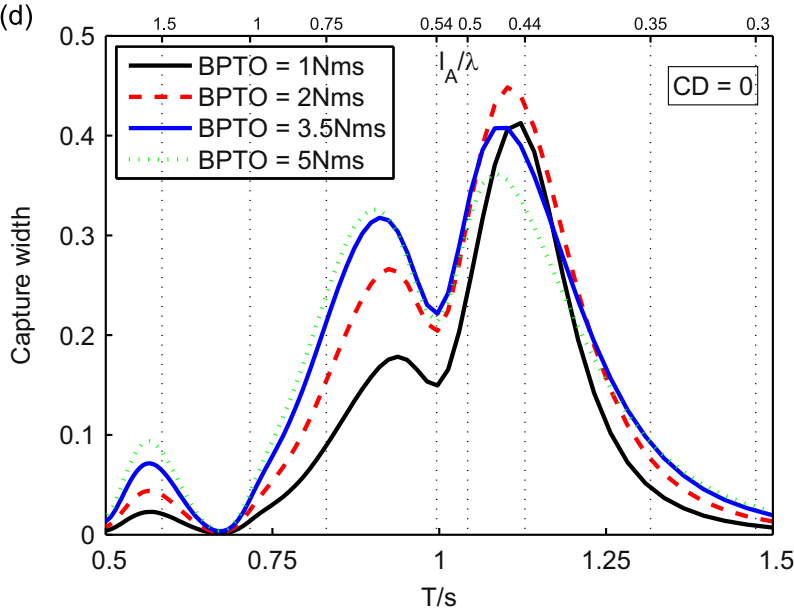

Fig. 13. Results from domed model in regular waves under various assumptions. (a) and (c) show hinge angle; (b) and (d) show capture width ratio.

shows the mean power out, while Fig. 12b plots the equivalent results as capture width ratios. The simulated results are based on ignoring drag $\left(C_{\mathrm{D}}=0\right)$. For the seven peak periods of the spectra defined for the experiments, the measured values of $H_{\mathrm{s}}$ and $B_{\mathrm{PTO}}$ were selected for the simulations. For the simulations at other values of $T_{\mathrm{p}}$, the averages of the experimental values of the two series of significant wave height were used $\left(H_{s}=0.027 \mathrm{~m}\right.$ and $\left.H_{s}=0.042 \mathrm{~m}\right)$; and similarly for the values of PTO coefficient $\left(B_{\text {PTO }}=3.81 \mathrm{~N} \mathrm{~ms}\right.$ and $B_{\text {PTO }}=3.01 \mathrm{~N} \mathrm{~ms}$ respectively). The agreement between these predictions and the experimental data is satisfactory: though it is not clear why the zero drag predictions underestimate the capture width ratios obtained from the experiments in the region of the peak value. There is not however a consistent under-prediction at the shorter periods, as was evident in the results for the flat-bottomed float device at $1 / 8$ th scale.

Results from some parameter studies of behaviour in regular waves of amplitude $0.02 \mathrm{~m}$ are shown in Fig. 13. The left hand column (Fig. 13a and c) presents the relative rotational angle between floats 2 and 3 (i.e. the angular displacement through which power is extracted); while the right hand column (Fig. 13b and d) shows the corresponding capture width ratios. The upper row indicates the influence of specifying different drag coefficients in the model. This of course is rather more evident in Fig. 13b because of the quadratic dependence of power on angle. The maximum capture width ratio is seen to reduce by about $13 \%$ for drag coefficients varying from 0 to 1.5. The lower row shows the influence of power take-off coefficient $B_{\text {PTO, when computed }}$ with a drag coefficient $C_{\mathrm{D}}=0$. The angle reduces as the PTO coefficient increases, as $B_{\text {PTO }}$ is a source of damping. But the influence on power is quite different. In addition to the effect just mentioned, there is an opposing one: the power, hence capture width ratio, increases with $B_{\text {PTO }}$, for a given rotational velocity. Hence the order of the four curves in Fig. 13d is not the same as that in (c). The combination of the two opposing effects is such that in this plot the red dashed line corresponding to $B_{\mathrm{PTO}}=2 \mathrm{~N}$ ms provides the highest peak capture width ratio, and the optimum value of $B_{\text {PTO }}$ is close to this.

In Fig. $13 \mathrm{c}$ and $\mathrm{d}$ the upper horizontal axis is scaled to show the ratio of float spacing $l_{\mathrm{A}}$ to wavelength $\lambda\left(l_{\mathrm{A}}\right.$ being the spacing between floats 1 and 2, or between 2 and 3). Based on consideration of quasistatic responses of each float, one would expect the angle discussed above to be maximised when this ratio is $(2 n-1) / 2$ for integer values of $n$, and to be zero for integer ratios. This is not inconsistent with Fig. $13 \mathrm{c}$, where there are maxima near $l_{\mathrm{A}} / \lambda=0.5$ and 1.5 , and a minimum near $l_{\mathrm{A}} / \lambda=1.0$. 
The dynamics of the system may be investigated by examining responses in its lowest few modes, and it is therefore of interest to perform an eigen analysis of the dynamic model. Philippe et al. (2013) adopted a somewhat similar approach in their investigation of a floating offshore wind turbine. We perform what is essentially a free vibration analysis to obtain modes and natural periods of the system, in the absence of damping and the PTO. The added mass, of course, depends on frequency, so the approach adopted here is to perform the eigen analysis over the complete range of frequencies of interest: i.e. at every frequency $\omega$, a set of eigen modes and eigen frequencies is evaluated from the mass and stiffness matrices corresponding to that frequency. If the resulting eigen frequency is equal to $\omega$, that is taken to be a natural frequency $\omega_{\mathrm{n}}$. The results of such an analysis of the $1: 40$ scale model with domed ends are given in Figs. 14 and 15. Computed eigen periods $T_{n}=2 \pi / \omega_{n}$ are plotted in Fig. 14, as well as the period $T=2 \pi / \omega$. The natural periods are located where the lines cross. If one assumes that the connections between the 3 floats are rigid, and there is one hinge at the PTO, the device has 4 degrees of freedom in the vertical plane, and 4 modes. Surge, however, is unrestrained (or very lightly restrained), so the natural period of the corresponding mode is very low. Fig. 15 shows the four modes, in a similar representation to Fig. 2. It appears that the lowest two vertical modes have closely spaced periods in the range $0.95-$ $1.15 \mathrm{~s}$, and both involve anti-phase motions of the two outside floats relative to the middle float. The figure also indicates the length to wave length ratio $l_{\mathrm{r}}=l_{\mathrm{A}} / \lambda$ corresponding to each natural period, and for these two modes the value is not far from 0.5 . This would appear to be an indication of a good design. It should also be noted that when excited by waves the response of the device in these modes is heavily damped by the PTO, so that effectively the modal responses overlap, leading to a broad-banded response amplitude operator (RAO) for the angle at the joint. This is very clear from Fig. 13c, in which two of the vertical gridlines correspond to the natural periods and wave length ratios of the two significant vertical modes.

\section{Further parametric studies}

\subsection{Response to oblique waves}

All the results so far have been for waves propagating along the axis of the device. It is assumed that the mooring system is defined so as to favour such a configuration, with the large float downstream of the two smaller floats. It is of interest

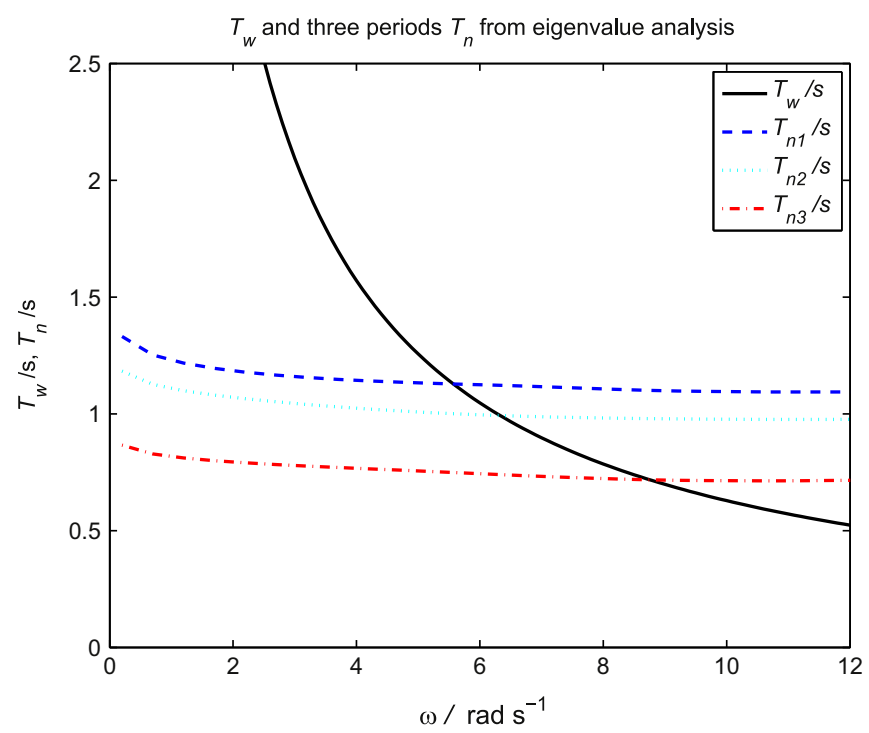

Fig. 14. Eigen periods $T_{\mathrm{n}}$ and wave period $T_{\mathrm{w}}$ plotted against wave frequency $\omega$.

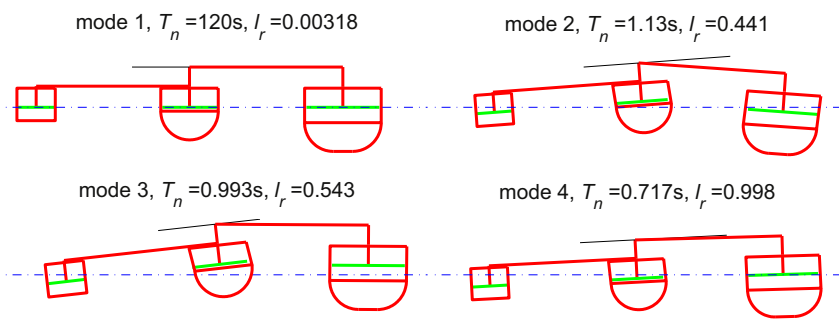

Fig. 15. Four eigen modes for the $1 / 40$ th scale model. 

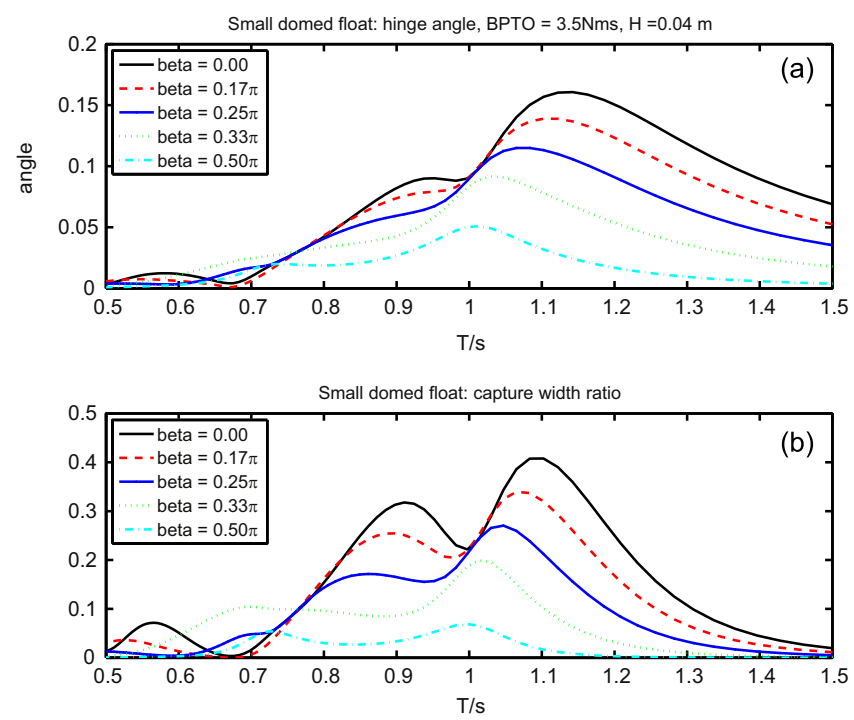

Fig. 16. Influence of orientation to waves $\beta$, for $1 / 40$ th scale domed model in regular waves. (a) Hinge angle; (b) capture width ratio.

however to consider how much the captured power is reduced for other wave directions. Fig. 16 shows results for waves encountering the base case 1/40th scale domed float model considered in Section 3. The upper plot shows the variation of hinge angle with wave period, and the lower plot shows the corresponding capture width ratio. The peak of the latter is approximately halved as the direction of the waves increases from $0^{\circ}$ to $45^{\circ}$ to the axis of the device. The figures also demonstrate that power is still extracted in beam seas: this is a consequence of the differential vertical responses of the different sized floats. The maximum capture width ratio in beam seas is about 0.07 .

\subsection{The influence of float separation}

Illustrative results have been obtained for a series of modified 1/40th scale devices, in which the separation between the domed floats is varied on either side of the base case $l_{A}=l_{B}=0.8 \mathrm{~m}$. It is assumed that nothing else has changed in these variants. The masses and mass moments of inertia are not modified, so the implicit assumption is that there are small changes to the properties of the structural elements, ballast, PTO, mass, etc. (though the PTO coefficient BPTO is unchanged). Fig. 17 shows the hinge angle, the capture width ratios and the power in regular waves propagating along the axis of each device. It is clear from the plots that small changes to the float spacing can cause quite significant changes in the responses: an increase from $0.8 \mathrm{~m}$ to $0.9 \mathrm{~m}$ appears to lead to an a $47 \%$ increase in the peak capture width ratio. But this peak power itself occurs at a shorter wave period, when the incident power is less; the power absorbed, therefore, is only increased by about $10 \%$.

It also appears that with a spacing of $0.9 \mathrm{~m}$ between the floats in the $1 / 40$ th scale device, the bandwidth of the absorbed power is considerably increased. The implications of this are shown in Fig. 18, where the results for such a device are obtained in JONSWAP sea-states $(\gamma=3.3)$ with the same significant wave height and peak periods as considered in Fig. 12. Both the mean power and the capture width ratios over the range of sea-states considered are higher for the case $l_{\mathrm{A}}=l_{\mathrm{B}}=0.9 \mathrm{~m}$ than for the base case configuration theoretical predictions in Fig. 12 . At $T_{\mathrm{p}}=1 \mathrm{~s}$, the capture width ratio is increased by about $40 \%$; the maximum power, at $T_{\mathrm{p}}=1.1 \mathrm{~s}$, is increased by about $17 \%$.

\subsection{Member flexibility}

In the preceding analysis, the stiffnesses of the individual members in the frames shown in Fig. 4 have been taken to be very large, relative to the hydrostatic stiffness of the floats. It is of interest to consider the effect of frame stiffness: to what extent, for example, might the power captured be modified by the flexibility of the structures? The methodology described above permits this to be investigated very easily. We illustrate this here with an example where the axial stiffness of the vertical bar projecting above the large float is varied (member 2 of frame B in Fig. 4). Fig. 19 compares the hinge angle, capture width ratio and average power in regular waves, plotted against wave period, for the base case considered in Fig. 16 and four variants. In these four the afore-mentioned axial stiffness is scaled by factors $A_{\mathrm{x}}$ in the range $5 \times 10^{-11}$ to $7 \times 10^{-12}$, chosen to highlight the range where the influence is most pronounced. As a point of reference, one can note that if the axial stiffness were scaled by $1.9 \times 10^{-11}$, it would be equal to the hydrostatic stiffness of float 3 .

The results in Fig. 19 suggest that within the range of stiffnesses considered, the major peak at about $T_{\mathrm{w}}=1.1 \mathrm{~s}$ is shifted to higher periods: for the lowest stiffness shown this peak is at $T_{\mathrm{w}}=1.7 \mathrm{~s}$. Confirmation that this is a resonance is obtained by performing a similar eigenvalue analysis to that on the base case configuration which gave the results shown in Fig. 15 . 

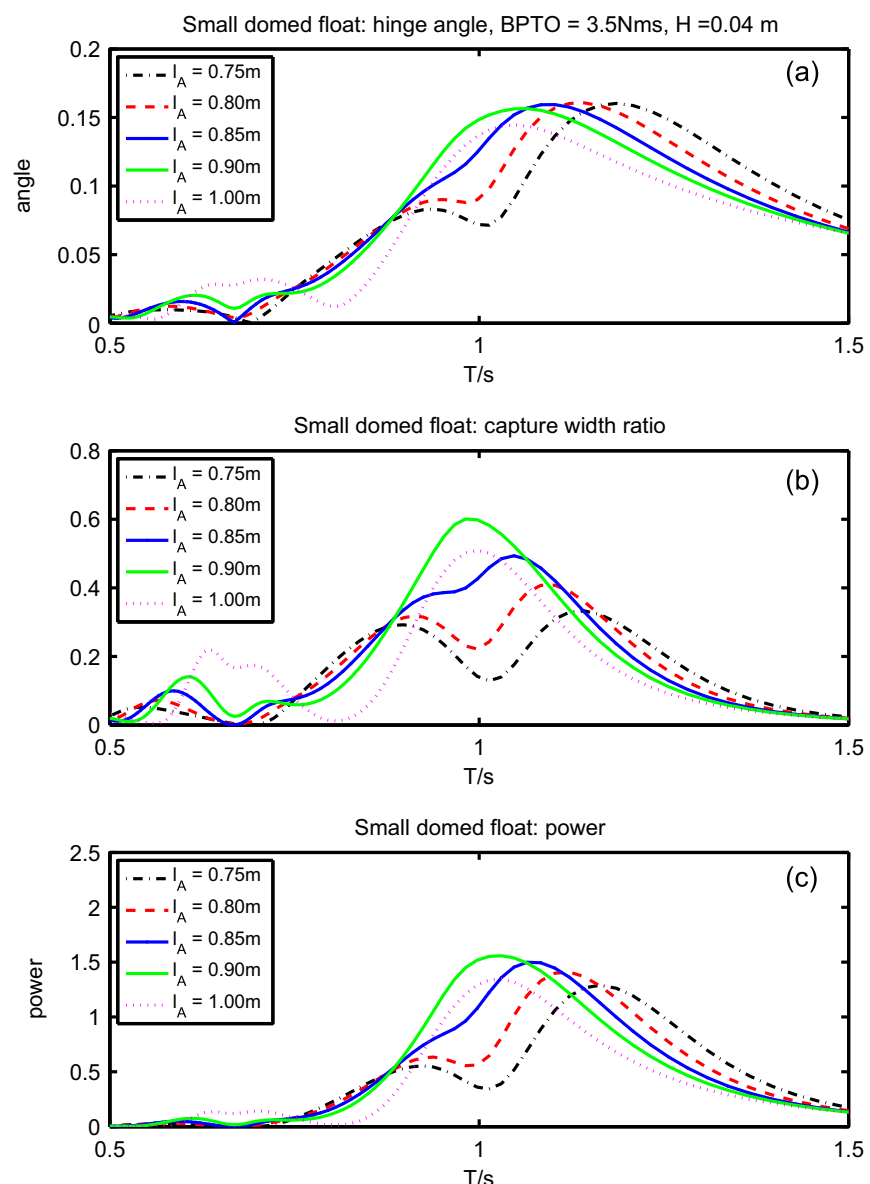

Fig. 17. Influence of varying float separation $I_{\mathrm{A}}$ for $1 / 40$ th scale domed model in regular waves. (a) Angle; (b) capture width ratio; (c) average power.
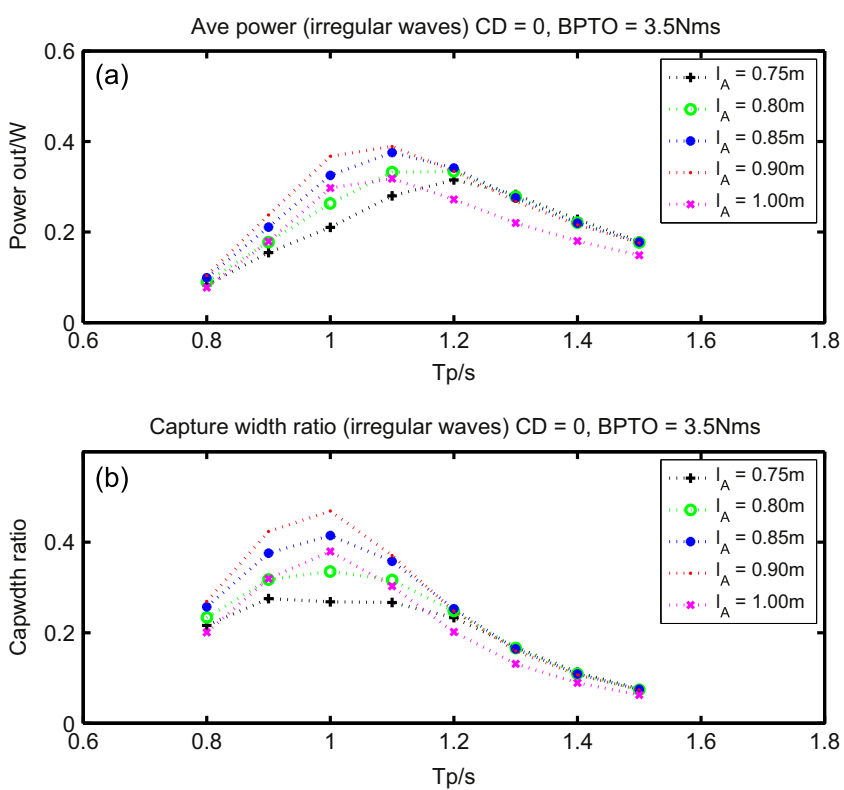

Fig. 18. Influence of varying float separation $I_{\mathrm{A}}$ for $1 / 40$ th scale domed model in irregular waves. (a) Mean power; (b) capture width ratio. 

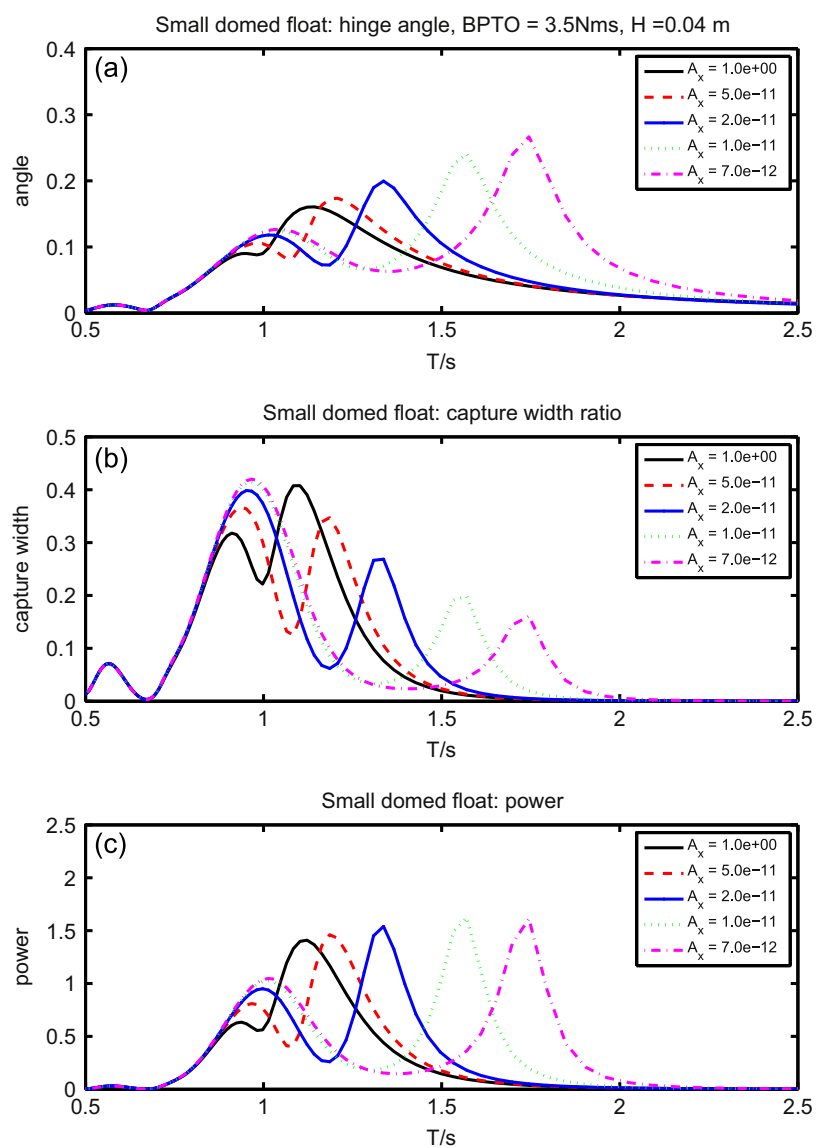

Fig. 19. Influence axial stiffness ratio ${ }_{\mathrm{Ax}}$ of member $\mathrm{B} 2$ for $1 / 40$ th scale domed model in regular waves. (a) Angle; (b) capture width ratio; (c) average power.

Table 2

Variation of natural periods with axial stiffness of member B2.

\begin{tabular}{llllll}
\hline Axial stiffness factor & 1 & $5 \times 10^{-11}$ & $2 \times 10^{-11}$ & $1 \times 10^{-11}$ & $7 \times 10^{-12}$ \\
\hline$T_{2} / \mathrm{s}$ & 1.13 & 1.20 & 1.34 & 1.57 & 1.75 \\
$T_{3} / \mathrm{s}$ & 0.993 & 1.03 & 1.04 & 1.05 & 1.05 \\
\hline
\end{tabular}

The difference is that for those results the system was essentially a series of linked rigid bodies with hydrostatic stiffness effects, whereas now the flexibility of the connecting structure has a crucial influence. Table 2 lists the periods of modes 2 and 3 for the range of stiffness scaling factors considered. The mode 4 period is unchanged (to 3 significant figures), and the modes look generally similar to those of the base case, except for the strong increase in hinge rotation in mode 2 at the smallest two values of stiffness scaling factor. Overall this limited investigation of member flexibility suggests that even substantial reductions in stiffness do not greatly compromise the power capacity of the device.

\section{Conclusions}

In this paper we have presented a method for modelling complex wave energy devices, comprising a series of floats connected by slender structural elements. The aim was a methodology permitting efficient and accurate analysis of the fluid-structure interactions under operating conditions extracting wave power, accounting for large body linear diffraction effects and potential flexibility in the connecting members. This has been achieved through a two-stage modelling process. The hydrodynamic problem is solved first for the individual floats responding in their rigid body modes. The dynamics of the total system are then analysed, using the method of substructuring (static condensation). An advantage of such an approach, illustrated here, is that the structural members may be varied, and the power take-off, as well as assumptions about drag coefficients, without it being necessary to re-compute any of the hydrodynamics. Furthermore, with the 
additional simplification that the floats are analysed as if there were no hydrodynamic interactions between them, the effect of the spacing between them may also be investigated, without any additional hydrodynamic analysis. Such considerations are particularly important if one needs to undertake an analysis where the power take-off is nonlinear. In such a case, it would be straightforward to extend the whole methodology presented here into the time domain, using the Cummins equation as described by Kim et al. (2013) and implemented using state space modelling by, for example, Taghipour et al. (2008) and Chen et al. (2014).

There are approximations inherent in the analysis, and uncertainties regarding the effects of viscosity on the responses of the floats. The comparisons of the results of this modelling with experimental data for two different devices (at different scales) tested in both regular and irregular long-crested seas, suggest that the approximations are not unreasonable. They lead to the following detailed findings:

1) The concept of capture width ratio is found to be a convenient way of collapsing the results under different wave conditions for devices of the type considered here. The exception is at the peaks of the power versus period plots, where if drag is significant it is confirmed that excitation at different wave heights yields different capture width ratios.

2) The model comprising floats with essentially flat ends is significantly affected by viscous drag. Incorporating drag effects through equivalent linearization, and comparison with the experiments in regular waves, leads to an estimate for the effective drag coefficient $C_{\mathrm{D}}$ of about 1.5 , with the assumptions made in the model. To obtain a fit in irregular waves, however, a drag coefficient of 0.4 was used which is similar to that obtained for heave motion using CFD. The difference is presently unexplained although it has been noted that weak reflections occurred in the tank with regular waves which would not be present in irregular waves, and a higher drag coefficient may be compensating for spurious effects.

3) The model having domed floats is very much less affected by drag effects. Good comparisons between experimental and theoretical results are in fact achieved ignoring drag completely.

4) The broad-banded nature of the response of the three float device implies that the response in random sea states whose peak periods are well away from the resonant peak in the power curves is not unduly compromised. Indeed, at short peak periods the model underestimates the experimentally obtained capture width ratios. The reason for this is not clear, but the effect of drag does appear to be less significant in these cases.

5) The model may be used to deduce optimum power take-off coefficient, and this has been illustrated.

6) Float spacing has also been investigated. The eigen analysis has demonstrated the trade-off between resonant periods of the system, and the ratio of float spacing to wave length.

7) Modelling the response of the system in waves propagating at an angle to the device shows the expected strong influence of directionality, but confirms that power is still generated in beam seas, with capture width ratio up to $20 \%$ of the maximum, because of the differential vertical responses of the differently sized floats.

8) A limited investigation of member flexibility, including an eigen analysis of the coupled system, suggests that even substantial reductions of member stiffness (as compared with hydrostatic stiffness) do not greatly prejudice the device performance. Further investigation is required to establish if it might even be possible to effect modest gains, by replacing a bar by a spring and second power take-off system: though practical design of such a system could be challenging.

The study to date has provided useful conclusions about how to model a device such as this, and how to consider its optimisation. The resulting model has proved useful in a separate study of the variability of wave power predictions for the M4 device over a representative operational life, in various locations in the North East Atlantic and the North Sea (Santo et al., 2016). Further investigation would be required to incorporate full hydrodynamic interaction into the analysis, and to model the viscous effects using CFD. All of this may be used in developing the detailed nonlinear analysis tools required to represent behaviour of wave energy devices under active control and in extreme sea conditions.

\section{Acknowledgements}

This work was supported by EPSRC through the Supergen Marine Challenge 2 grant Step-WEC (EP/K012487/1).

\section{References}

Arinaga, R.A., Cheung, K.F., 2012. Atlas of global wave energy from 10 years of reanalysis and hindcast data. Renewable Energy 39, 49-64.

Babarit, A., Hals, J., Muliawan, M.J., Moan, T., Krokstad, J., 2012. Numerical benchmarking study of a selection of wave energy converters. Renewable Energy 41, 44-63.

Babarit, A., 2015. A database of capture width ratio of wave energy converters. Renewable Energy 80, 610-628.

Bryden, I.G., 2006. The marine energy resource, constraints and opportunities. Proceedings of the Institution of Civil Engineers, Maritime Engineering 159, 55-65.

Cahill, B., Lewis, A., 2014. Wave period ratios and the calculation of wave power. In: Proceedings of the 2nd Marine Energy Technology Symposium, Seattle, USA.

Chen, M.S., Eatock Taylor, R., Choo, Y.S., 2014. Time domain modeling of a dynamic impact oscillator under wave excitations. Ocean Engineering 76, 40-51. Cruz, J., 2008. Ocean Wave Energy: Current Status and Future Perspectives. Springer, Bristol, United Kingdom. 
Eatock Taylor, R., Zietsman, J., 1981. A comparison of localised finite element formulations for two dimensional wave diffraction and radiation problems. International Journal of Numerical Methods in Engineering 17, 1355-1384.

Eatock Taylor, R., Taylor, P.H., Drake, K.R., 2009. Tank wall reflections in transient testing. In: Proceedings of Twenty Fourth International Workshop on Water Waves and Floating Bodies, Zelenogorsk, Russia.

EPRI, 2011. Mapping and Assessment of the United States Ocean Wave Energy Resource. Electric Power Research Institute, Palo Alto, USA.

Evans, D.V., 1976. A theory for wave-power absorption by oscillating bodies. Journal of Fluid Mechanics 77, 1-25.

Evans, D.V., 1981. Power from water waves. Annual Review of Fluid Mechanics 13, 157-187.

Evans, D.V., Porter, R., 1997. Near-trapping of waves by circular arrays of vertical cylinders. Applied Ocean Research 19, $83-99$.

Evans, D.V., Porter, R., 2012. Wave energy extraction by coupled resonant absorbers. Philosophical Transactions of the Royal Society A370, 315-344.

Falcão, A.F. de O., 2010. Wave energy utilization: a review of the technologies. Renewable and Sustainable. Energy Reviews 14, 899-918.

Falnes, J., 2007. A review of wave-energy extraction. Marine Structures 20, 185-201.

Farley, F.J.M., Rainey, R.C.T., Chaplin, J.R., 2012. Rubber tubes in the sea. Philosophical Transactions of the Royal Society of London A $370,381-402$.

Garrett, C.J.R., 1971. Wave forces on a circular dock. Journal of Fluid Mechanics 46, 129-139.

Greaves, D., Smith, G., Attrill, M., Belmont, M., Chadwick, A., Conley, D., Eccleston, A., Godley, B., Harrington, N., Hor, C.L., Hosegood, P., Johanning, L., Pan, S., Reeve, D., Williams, J., Wolfram, J., Xu, J., Zobaa, A., Zou, Q., 2009. Marine renewable energy development - research, design, install. Proceedings of the Institution of Civil Engineers, Maritime Engineering 162, 187-196.

Hung, S.M., 1981. Hydrodynamic Loads on Axisymmetric Bodies. University College London.

Kim, B.W., H.G., Kim, J.H., Hong, S.A., 2013. Comparison of linear spring and nonlinear FEM methods in dynamic coupled analysis of floating structure and mooring system. Journal of Fluids and Structures 42, 205-227.

Krylov, N., Bogoliubov, N., 1943. Introduction to nonlinear mechanics. In: Lefshetz, S. (Ed.), Annals of Mathematical Studies, No. 11, Princeton University Press, NJ.

Lee, C.H., Newman, J.N., 1991. The computation of second-order wave loads. In: Proceedings of the 10th International Conference on Offshore Mechanics and Arctic Engineering (OMAE).

López, I., Andreu, J., Ceballos, S., Martínez de Alegría, I., Kortabarria, I., 2013. Review of wave energy technologies and the necessary power-equipment Renewable and Sustainable Energy Reviews 27, 413-434.

Malhotra, A.K., Penzien, J., 1970. Non-deterministic analysis of offshore structures. Journal of Engineering Mechanics Division, American Society of Civil Engineers 96 (EM6), 985-1003.

Mollison, D., Buneman., O.P., Salter, S.H., 1976. Wave power availability in the N.E. Atlantic. Nature 263, $223-226$.

Newman, J.N., 1976. The interaction of stationary vessels with regular waves. In: Proceedings of Eleventh Symposium on Naval Hydrodynamics, Office of Naval Research, University College London, UK, 491-502.

Newman, J.N., 1977. Marine Hydrodynamics. MIT Press, Cambridge, MA, USA.

Philippe, M., Babarit, A., Ferrant, P., 2013. Modes of response of an offshore wind turbine with directional wind and waves. Renewable Energy 49, 151-155.

Przemieniecki, J.S., 1985. Theory of Matrix Structural Analysis. Dover, New York, USA.

Santo, H., Taylor, P.H., Eatock Taylor, R., Stansby, P.K., 2016. Decadal variability of wave power production in the North-East Atlantic and North Sea for the M4 machine. Renewable Energy 91, 442-450.

Stansby, P.K., Carpintero Moreno, E., Stallard, T., Maggi, A., Eatock Taylor, R., 2014. Wave energy conversion with high capture width by the three-float line absorber M4. In: Proceedings of 1st International Conference on Renewable Energies Offshore, RENEW2014, Lisbon, Portugal.

Stansby, P.K., Carpintero Moreno, E., Stallard, T., Maggi, A., 2015a. Three-float broad-band resonant line absorber with surge for wave energy conversion. Renewable Energy 78, 132-140.

Stansby, P.K., Carpintero Moreno, E., Stallard, T., 2015b. Capture width of the three-float multi-mode multi-resonance broad-band wave energy line absorber M4 from laboratory studies with irregular waves of different spectral shape and directional spreading. Journal of Ocean Engineering and Marine Energy 1, 287-298.

Stansby, P.K., Gu, H., Carpintero Moreno, E., Stallard, T., 2015c. Drag minimisation for high capture width with three float wave energy converter M4. In: Proceedings of 11th European Wave and Tidal Energy Conference (EWTEC), Nantes, France.

Sun, L., Taylor, P.H., Eatock Taylor, R., 2010. First and second order analysis of resonant waves between adjacent barges. Journal of Fluids and Structures 26 954-978.

Sun, L., Choo, Y.S., Eatock Taylor, R., 2011. Responses of interconnected floating bodies. The IES. Journal Part A: Civil Structural Engineering 4, 143-156.

Sun, L., Choo, Y.S., Eatock Taylor, R., Llorente, C., 2012. Responses of floating bodies with flexible connections. In: Proceedings of Marine Operations Specialty Symposium, MOSS 2012, 6-8 August 2012, Singapore.

Taghipour, R., Pérez, T., Moan, T., 2008. Hybrid frequency-time domain models for dynamic response analysis of marine structures. Ocean Engineering 35 , $685-705$.

Wolgamot, H., Eatock Taylor, R., Taylor, P.H., 2014. Radiation, trapping and near-trapping in arrays of surface-piercing cylinders. Journal of Engineering Mathematics 91, 17-35.

Wolgamot, H., FitzGerald, C.J., 2015. Nonlinear hydrodynamic and real fluid effects on wave energy devices. Proceedings of the Institution of Mechanical Engineers, Part A: Journal of Power and Energy 229, 772-794.

Yemm, R., Pizer, D., Retzler, C., Henderson, R., 2012. Pelamis: experience from concept to connection. Philosophical Transactions of the Royal Society A370, 365-380.

Yeung, R.W., 1981. Added mass and damping of a vertical cylinder in finite-depth waters. Applied Ocean Research 3, $119-133$. 